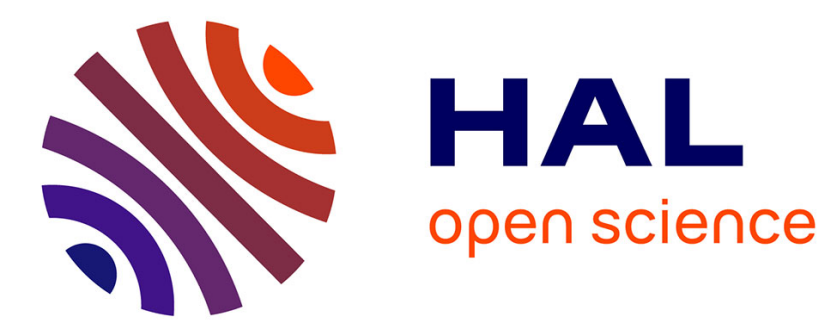

\title{
The Optimal Inflation Rate with Discount Factor Heterogeneity
}

\author{
Antoine Lepetit
}

\section{To cite this version:}

Antoine Lepetit. The Optimal Inflation Rate with Discount Factor Heterogeneity. 2017. hal01527816v3

\section{HAL Id: hal-01527816 \\ https://hal.science/hal-01527816v3}

Preprint submitted on 15 Nov 2018

HAL is a multi-disciplinary open access archive for the deposit and dissemination of scientific research documents, whether they are published or not. The documents may come from teaching and research institutions in France or abroad, or from public or private research centers.
L'archive ouverte pluridisciplinaire HAL, est destinée au dépôt et à la diffusion de documents scientifiques de niveau recherche, publiés ou non, émanant des établissements d'enseignement et de recherche français ou étrangers, des laboratoires publics ou privés. 


\title{
The Optimal Inflation Rate with Discount Factor
}

\section{Heterogeneity}

\author{
Antoine Lepetit*
}

November 2018

\begin{abstract}
This paper shows that deviations from long-run price stability are optimal in the presence of price stickiness whenever profit and utility flows are discounted at a different rate. In that case, a monetary authority acting under commitment will choose a path for the inflation rate that ends with a non-zero value. Such a property is relevant in a wide range of macroeconomic environments. I first illustrate this by studying optimal monetary policy in a New Keynesian model with a perpetual youth structure. In this setting, profit flows are discounted more heavily than utility flows and the optimal inflation target is equal to 3.2 percent in a baseline calibration of the model. I also show that this property leads to a positive long-run inflation rate in models with firm entry and exit and in environments with search and matching frictions in the labor market and another form of nominal rigidity, wage stickiness.
\end{abstract}

Keywords: optimal inflation rate, inflation target, sticky prices, optimal monetary policy, discount factor heterogeneity, perpetual youth model

JEL Codes: E31, E32, E52

\footnotetext{
*Board of Governors of the Federal Reserve System, Division of Research and Statistics, 20th St. and Constitution Ave., NW, Washington, DC 20551 (e-mail: Antoine.Lepetit@frb.gov). I thank Florin Bilbiie, Ippei Fujiwara, Francesco Furlanetto, Erwan Gautier, Jordan Roulleau-Pasdeloup, and participants in various seminars and conferences for their comments and suggestions, and Shannon Luk for editorial assistance. All remaining errors are my own. The views expressed in this paper are solely the responsibility of the author and should not be interpreted as reflecting the views of the Board of Governors of the Federal Reserve System.
} 


\section{Introduction}

Most central banks in advanced economies have adopted inflation targets of 2 percent per year. The European Central Bank officially chose this target as early as 2003. In the United States, although the Federal Reserve had been aiming for 2 percent inflation since the mid-1990s, the target was not made official until 2012 (Summers et al. 2018). Policymakers generally argue that this figure strikes a balance between the necessity to provide a hedge against the risk of hitting the zero lower bound on nominal interest rates and the costs associated with positive steady-state inflation. In macroeconomic models used for policy analysis, these costs arise mainly from the presence of price stickiness. Taken in isolation, this friction has been shown to imply that long-run price stability is optimal (Woodford 2003).

This paper revisits this last conclusion. It shows that, in environments with sticky prices, a long-run inflation rate of zero is not optimal if profit and utility flows are discounted at a different rate.

The optimality of zero inflation in sticky-price models is often thought to arise from the verticality of the long-run Phillips curve. Instead, in earlier contributions, King and Wolman (1999) and Woodford (2003) have showed that the rationale behind this result is more complex. When prices are sticky, the effects of inflation on real outcomes are intrinsically dynamic. An increase in the time $t$ inflation rate decreases markups at time $t$ but may increase markups before time $t$ through expected inflation. Because firms discount the future, these effects are asymmetric and average markups can be reduced by deviating from price stability. In other words, the long-run Phillips curve is not vertical. However, when choosing a path for the inflation rate, a monetary authority acting under commitment weights the consequences of its choices according to their distance in the future. This discounting effect perfectly offsets the effect of inflation on average markups when the private discount rate - that is, the rate of firms - which partly determines the slope of the long-run Phillips curve, and the social discount rate, which determines the strength of the weighting effect, are equal. In that case, the discounted effect of inflation on markups is equal to zero, and the monetary authority should focus on minimizing the resource costs associated with price stickiness. Long-run price stability is optimal. In the literature, little attention has been paid to cases where social and private discount rates differ. This paper fills this gap. It shows that such a heterogeneity in discount factors arises endogenously in several macroeconomic environments and that it justifies the adoption of moderately positive inflation 
targets, even in the absence of the zero lower bound on nominal interest rates.

I first consider a New Keynesian model with an overlapping generation structure, as in Blanchard's (1985) and Yaari's (1965) perpetual youth model. On the firm side, monopolistic producers face quadratic costs of price adjustment. This gives rise to a Phillips curve relating markups to inflation. On the household side, individuals accumulate wealth over their lifetimes, and generations differ in their consumption and labor supply decisions. In relation with this heterogeneity, the real interest rate, according to which firms discount profit flows, is larger than the household discount rate. The decentralized equilibrium is inefficient for several reasons. First, monopolistic competition introduces a wedge between the marginal rate of substitution between consumption and leisure and the marginal product of labor. Second, the distribution of consumption and hours worked among households is suboptimal as young cohorts consume too little compared to older ones. Through its effect on markups and the resource costs of price adjustment, an increase in inflation redistributes income and can partially correct for these inefficiencies. The reduction in markups shifts labor demand and leads to an increase in wages and hours worked. Along with the increase in the resource costs incurred by firms, it also reduces profits and dividends. Thus, an increase in inflation benefits young generations, who rely disproportionately on labor income, and harms older generations, who rely mainly on capital income.

In this environment, the long-run optimal inflation rate is positive as long as the social discount rate, according to which the planner evaluates the lifetime utilities of generations, is lower than the real interest rate. Moreover, the optimal inflation target decreases as the social discount rate increases. This happens for two reasons. First, following the logic outlined above, the discounted effect of inflation on markups decreases as the gap between private and social discount rates shrinks. Second, the relative weight on young generations in aggregate welfare declines as the social discount rate rises. As a result, manipulating markups to redistribute consumption from young to older households becomes less beneficial. In the limit case where the social discount rate is equal to the real interest rate, the discounted effect of inflation on markups is equal to zero, and therefore, so is the optimal inflation target. Quantitatively, deviations from long-run price stability can be quite significant, even when the gap between the real interest rate and the social discount rate is small. In a baseline calibration of the model, and under the assumption that the monetary authority treats all generations equally, the optimal inflation rate is equal to 3.2 percent in annual terms. 
Some existing results in the optimal monetary policy literature can also be understood in light of this connection between discount factor heterogeneity and the optimal inflation rate. Bilbiie et al. (2014) develop a model with firm entry and exit and show that deviations from long-run price stability are optimal when the steady state is inefficient. They argue that a plausible calibration justifies an optimal inflation target of 2 percent or higher. In their framework, firms exit the market with positive probability in each period. As a result, the effective discount factor appearing in the Phillips curve is larger than the household discount factor. I rederive their optimal monetary policy problem and show that, regardless of the degree of steady-state inefficiency, the long-run optimal inflation rate is equal to zero when the Ramsey planner evaluates utility flows according to this effective discount factor instead of the discount factor of households. Furthermore, this property also applies to settings with imperfect competition and nominal stickiness in other markets. In order to show that, I build a model with search and matching frictions in the labor market and nominal wage stickiness. As shown in Arseneau and Chugh (2008), in this setting, an increase in inflation reduces average wage markups (or workers' bargaining power). Importantly, the effects of inflation are dynamic. An increase in the time $t$ inflation rate reduces the wage markup at time $t$ but increases it at time $t-1$ through expected inflation. When negotiating wages, firms and workers take into account that they might separate in the future. This implies that the effective discount factor used in wage negotiations is lower than the household discount factor by a factor depending on the amount of labor market turnover. I derive the Ramsey optimal monetary policy and show that it features a steady state with positive inflation when the monetary authority evaluates utility flows using the household rate of time preference. However, when the social discount factor is equal to the effective discount factor used during wage negotiations, the discounted effect of inflation on wage markups is equal to zero, and consequently, so is the optimal inflation target.

Apart from the aforementioned studies, this paper is related to a wide literature on the optimal inflation rate surveyed in Schmitt-Grohé and Uribe (2010) and Diercks (2017). In particular, recent contributions by Coibion et al. (2012) and Galí et al. (2018), Carlsson and Westermark (2016), and Adam and Weber (2017) show, respectively, that the zero lower bound on nominal interest rates, the combination of labor market frictions and wage-setting externalities, and firm-level heterogeneity in productivity may provide justifications for moderately positive inflation targets. From an empirical standpoint, the key channel through which an increase in inflation transmits to real activity in this paper, namely a reduction in markups, finds support in studies by Benabou (1992) on data from the 
U.S. retail trade sector and Banerjee and Russell (2001) on data from the G7 economies and Australia. Moreover, this paper is not the first to incorporate a perpetual youth structure in a New Keynesian setting. Previous studies have considered such a framework to study how monetary policy should respond to stock market conditions (Castelnuovo and Nisticò 2010, Nisticò 2012), or asset price bubbles (Galí 2017). Del Negro et al. (2015) show that it can provide a resolution to the excess sensitivity of macroeconomic variables to announcements about the future path of the policy rate in standard New Keynesian models, the so-called forward guidance puzzle. Two papers belonging to this literature are of especially close relevance. Nisticò (2016) studies optimal monetary policy in a model with both rule of thumb households and financial market participants who face a finite planning horizon, as in a perpetual-youth model. In order to use a linear-quadratic approach to optimal monetary policy analysis, he assumes that the zero-inflation steady state is efficient and focuses on the behavior of the central bank in response to shocks. On the contrary, one key contribution of this paper is to provide a derivation of the long-run behavior of optimal monetary policy in a heterogeneous agent New Keynesian perpetual youth model when the steady state is inefficient. However, I am not able to characterize the optimal behavior of the monetary authority along the business cycle. In a recent contribution, Cotton (2018) uses a New Keynesian model with overlapping generations to show that an increase in average inflation may lower the equilibrium real interest rate, thereby reducing the central bank's incentives to raise the inflation target in the face of the zero lower bound on nominal interest rates. In contrast, in this paper, deviations from long-run price stability arise from differences in private and social discounting, and not from the presence of the zero lower bound on nominal interest rates.

The paper is organized as follows. Section 2 shows that the optimality of zero inflation in the standard New Keynesian model is the result of two offsetting forces. Section 3 studies the long-run behavior of optimal monetary policy in a New Keynesian model with a perpetual youth structure. Section 4 shows that differences between private and social discount factors also give rise to positive optimal inflation rates in environments with firm entry and exit as well as in models with labor market frictions and nominal wage stickiness. Section 5 concludes. 


\section{Optimal long-run inflation in the standard New Keynesian model}

This section shows that the optimality of long-run price stability in the standard New Keynesian model stems from the canceling out of two opposing forces, an average markup effect and a weighting effect. This finding is not new (King and Wolman 1999 and Woodford 2003, Chapter 6). However, this exercise helps explains the main mechanisms at work and sets the stage for the analysis of optimal monetary policy in richer environments where one effect may dominate the other.

\subsection{A simple formula for the optimal inflation rate}

Consider a standard New Keynesian model without capital, as outlined for example in Galí (2008). The dynamics of the economy can be described by a Euler equation (1), an equation equating labor supply and labor demand (2), a resource constraint (3), as well as equations describing the price-setting behavior of firms, the behavior of monetary policy, and the dynamics of a technological factor $Z_{t}$.

$$
\begin{gathered}
\beta E_{t} \frac{1+R_{t}}{\Pi_{t+1}} \frac{U_{c}\left(C_{t+1}\right)}{U_{c}\left(C_{t}\right)}=1 \\
\frac{v_{L}\left(L_{t}\right)}{U_{c}\left(C_{t}\right)}=m c_{t} F_{L}\left(L_{t}\right) \\
\frac{F\left(L_{t}\right)}{s_{t}}=C_{t}
\end{gathered}
$$

$\beta$ is the discount factor of households, $R_{t}$ is the nominal interest rate set by the central bank, $\Pi_{t}$ is gross inflation, $C_{t}$ is consumption, $L_{t}$ is the number of hours worked, $m c_{t}$ is the marginal cost of firms, and $s_{t}$ is a wedge arising from the presence of costly price adjustment. Household utility depends positively on consumption and negatively on the number of hours supplied in a separable way $U\left(C_{t}, L_{t}\right)=U\left(C_{t}\right)-v\left(L_{t}\right)$. Firms produce with labor according to the production technology $F\left(L_{t}\right)$. In what follows, I assume the following functional forms for analytical convenience; $F\left(L_{t}\right)=Z_{t} L_{t}$,

$U\left(C_{t}\right)=\log \left(C_{t}\right)$, and $v\left(L_{t}\right)=\chi \frac{L_{t}^{1+\varphi}}{1+\varphi}$, where $\varphi$ is the inverse of the Frisch elasticity of labor supply and $\chi$ is a scaling factor. Depending on the model of price-setting behavior under consideration, the resource costs of inflation $s_{t}$ and marginal cost $m c_{t}$ are potentially functions of all past, current, and 
future inflation rates

$$
\begin{gathered}
m c_{t}=\Omega\left(\Pi_{t-i}, \ldots, \Pi_{t}, \ldots, E_{t} \Pi_{t+i}\right) \\
s_{t}=\Upsilon\left(\Pi_{t-i}, \ldots, \Pi_{t}, \ldots, E_{t} \Pi_{t+i}\right)
\end{gathered}
$$

where equation (4) is the Phillips curve of the model, $\Omega$ and $\Upsilon$ depend on the price-setting model, and $i \in \mathbb{N}^{+}$.

We are now in a position to derive a simple formula that relates the optimal inflation rate to the discounted effects of inflation on marginal costs and on resource costs. I consider the problem of a monetary authority acting under commitment and look at the steady state to which it would like to converge in the long run. In this scenario, the central bank chooses a path $\left\{R_{t}\right\}_{t=0}^{\infty}$ in order to maximize intertemporal utility $E_{0} \sum_{t=0}^{\infty} \xi^{t} U\left(C_{t}, L_{t}\right)$ subject to the constraints of the competitive economy, where the social discount factor $\xi$ may differ from the household discount factor $\beta^{1}$. The constraints to the maximization problem are equations (1), (2), (3), (4), and (5). The problem can be simplified in several ways. First, note that it is possible to use equations (2) and (3) to solve for consumption $C_{t}$ and hours $L_{t}$ as a function of $m c_{t}$ and $s_{t}$

$$
\begin{gathered}
L_{t}=\left[\frac{m c_{t} s_{t}}{\chi}\right]^{\frac{1}{1+\varphi}} \\
C_{t}=Z_{t}\left[\frac{m c_{t}}{\chi}\right]^{\frac{1}{1+\varphi}} s_{t}^{-\frac{\varphi}{1+\varphi}}
\end{gathered}
$$

Second, $m c_{t}$ and $s_{t}$ are potentially functions of all past, present, and future inflation rates. This implies, through equation (1), that choosing a sequence $\left\{R_{t}\right\}_{t=0}^{\infty}$ is equivalent to choosing a sequence for inflation $\left\{\Pi_{t}\right\}_{t=0}^{\infty}$. Thus, the Ramsey problem amounts to choosing $\left\{\Pi_{t}\right\}_{t=0}^{\infty}$ to maximize the following objective function

$$
E_{0} \sum_{t=0}^{\infty} \xi^{t}\left\{\log \left[Z_{t}\left[\frac{m c_{t}}{\chi}\right]^{\frac{1}{1+\varphi}} s_{t}^{-\frac{\varphi}{1+\varphi}}\right]-\frac{m c_{t} s_{t}}{1+\varphi}\right\}
$$

\footnotetext{
${ }^{1}$ In such a setting with a single representative household, a natural objective for the planner would be to maximize the lifetime utility of this representative household $E_{0} \sum_{t=0}^{\infty} \beta^{t} U\left(C_{t}, L_{t}\right)$. The assumption $\xi \neq \beta$ may thus seems unrealistic, however, note that it is simply made for expositional purposes as it helps shed light on the main mechanisms at work.
} 
where the links between $s_{t}, m c_{t}$, and inflation rates in different periods are given by equations (4) and (5). The first-order condition of this problem can be expressed as

$$
E_{0}\left\{\sum_{h=-t}^{\infty}\left[m c_{t+h}^{-1}-s_{t+h}\right]\left(\xi^{t+h} \frac{\partial m c_{t+h}}{\partial \Pi_{t}}\right)-\sum_{h=-t}^{\infty}\left[\varphi s_{t+h}^{-1}+m c_{t+h}\right]\left(\xi^{t+h} \frac{\partial s_{t+h}}{\partial \Pi_{t}}\right)\right\}=0
$$

The optimal inflation rate depends on 1) the discounted effect of current inflation on marginal costs in all periods; 2) the discounted effect of current inflation on resource costs in all periods; and 3) weights that are related to the degree of steady-state inefficiency. The equation makes clear that the effects of inflation on real outcomes are dynamic and that these outcomes are assigned a different weight by the monetary authority depending on their distance in the future. Moreover, note that in an efficient steady state with zero inflation, both marginal costs and resources costs are constant and equal to 1 , and the first term in the equation drops out. Indeed, in such a situation, output is at its optimal level, and the monetary authority has no incentives to influence it through marginal costs. In what follows, I leave aside this particular case and consider that the steady state is inefficient.

\section{$2.2 \quad$ A specific case: Rotemberg pricing}

I now take a closer look at the elements in equation (9) when firms face deadweight costs of adjusting prices as in Rotemberg (1982). In appendix 1, I also derive analytical formulas for the objects presented in equation (9) when firms have an exogenous probability of being able to reset their price (Calvo 1983).

The deadweight costs of adjusting prices have the same composition as the consumption basket and are

proportional to aggregate output $\Psi_{t}=\frac{\phi^{p}}{2}\left(\Pi_{t}-1\right)^{2} Y_{t}$. In such a setting, the optimal pricing condition of firms leads to the following relationship between marginal cost and inflation

$$
1-\theta+\theta m c_{t}-\phi^{p} \Pi_{t}\left(\Pi_{t}-1\right)+\beta \phi^{p} E_{t} \Pi_{t+1}\left(\Pi_{t+1}-1\right) \frac{1-\frac{\phi^{p}}{2}\left(\Pi_{t}-1\right)^{2}}{1-\frac{\phi^{p}}{2}\left(\Pi_{t+1}-1\right)^{2}}=0
$$

where $\theta$ is the elasticity of substitution between goods. Moreover $s_{t}$ is given by

$$
s_{t}=\frac{1}{1-\frac{\phi^{p}}{2}\left(\Pi_{t}-1\right)^{2}}
$$


Thus, with Rotemberg pricing, $s_{t}$ is a function of $\Pi_{t}$, and $m c_{t}$ is a function of $\Pi_{t}$ and $E_{t} \Pi_{t+1}$. Equation (9) simplifies to

$$
E_{0}\{\underbrace{\left[m c_{t-1}^{-1}-s_{t-1}\right] \xi^{-1} \frac{\partial m c_{t-1}}{\partial \Pi_{t}}+\left[m c_{t}^{-1}-s_{t}\right] \frac{\partial m c_{t}}{\partial \Pi_{t}}}_{\Lambda_{t}}-\underbrace{\left[\varphi s_{t}+m c_{t}\right] \frac{\partial s_{t}}{\partial \Pi_{t}}}_{\Gamma_{t}}\}=0
$$

where $\Lambda_{t}$ is the effect of inflation on utility operating through marginal cost and $\Gamma_{t}$ is the effect of inflation on utility operating through the resource costs of price adjustment. In steady state, they are equal to

$$
\begin{gathered}
\Lambda=\left[m c(\Pi)^{-1}-s(\Pi)\right] \frac{\phi^{p}}{\theta}\left[\left(\frac{\beta}{\xi}-1\right)(1-2 \Pi)+\left(1-\frac{1}{\xi}\right) \beta \frac{\phi^{p} \Pi(\Pi-1)^{2}}{1-\frac{\phi^{p}}{2}(\Pi-1)^{2}}\right] \\
\Gamma=\left[\varphi s(\Pi)^{-1}+m c(\Pi)\right] \frac{\phi^{p}(\Pi-1)}{\left[1-\frac{\phi^{p}}{2}(\Pi-1)^{2}\right]^{2}}
\end{gathered}
$$

where the absence of time subscripts denotes steady-state values and the notations $m c(\Pi)$ and $s(\Pi)$ indicate that steady state marginal costs and resource costs are functions of inflation through equations (10) and (11). Resource costs depend only on current inflation and are minimized when inflation is equal to zero $(\Pi=1)$. More interestingly, the discounted effect of current inflation on past and present marginal costs depends on the ratio of the social discount factor $\xi$ and the discount factor of the private sector $\beta$. When the two are equal, $\Lambda=0$ when $\Pi=1$. This result can be understood by considering the unweighted effect of current inflation on the sum of past and present marginal costs $\frac{\partial m c_{t-1}}{\partial E_{t-1} \Pi_{t}}+\frac{\partial m c_{t}}{\partial \Pi_{t}}$. In steady state, it is equal to

$$
(1-\beta) \frac{\phi^{p}}{\theta}(2 \Pi-1)
$$

Since adjusting prices is costly, firms do not pass on the entirety of movements in marginal costs to prices, and current inflation is associated with a reduction in markups. According to the same logic, expected future inflation leads firms to set higher markups in order to minimize future price adjustments costs. However, these effects are asymmetric. Since firms discount the future with factor $\beta$, higher inflation in $t$ has a larger positive effect on marginal cost at time $t$ than a negative effect at time $t-1$. In other words, the model features a positive long-run relationship between inflation and marginal cost, as can be seen from the above expression. These outcomes, which happen in successive 
periods, are weighted differently by the Ramsey planner. Events occurring at time $t-1$, which are closer in the future, receive a higher weight than events occurring at time $t$. When social and private discount rates are equal, this weighting effect fully offsets the effect of inflation on average markups, and the effect of inflation on the discounted sum of markups is equal to zero. The inflation rate is then set equal to zero in order to minimize resource costs. However, when social and private discount rates differ, one effect dominates the other, and the optimal inflation rate is different from zero. This can be seen in figure 1 , which plots $\Lambda$ and $\Gamma$ for different values of the ratio $\xi / \beta$.

When $\xi=\beta, \Lambda$ is equal to zero when $\Pi=1$ (figure 1 , first panel). In that case, the monetary authority seeks to maximize the lifetime utility of households, and zero inflation is optimal. This is the standard result from the literature. When $\xi=1$, the planner gives an equal weight to outcomes happening in different periods. In the absence of any weighting effect, $\Lambda$ is positive for a large range of values of $\Pi$ and the optimal inflation rate is positive (figure 1 , second panel). In the third case, $\xi$ is lower than $\beta$. The monetary authority now puts a larger relative weight on the adverse effects of inflation happening before time $t$ than on its beneficial effects happening at time $t ; \Lambda$ is negative for a large range of values of $\Pi$, and the optimal inflation rate is negative (figure 1, third panel).

\section{Optimal long-run inflation in a New Keynesian model with a perpetual youth structure}

In order to build intuition, the preceding analysis focused on a simple model and imposed the heterogeneity in discount factors in an exogenous manner. I now develop a model in which this heterogeneity arises endogenously. I incorporate an overlapping generation structure, as in Blanchard's (1985) and Yaari's (1965) perpetual youth model, in the simple New Keynesian model of section 2. As emphasized in the introduction, such a framework has been used before for different purposes. Therefore, the novelty does not lie in the model itself but in the fact that I solve for the steady state of the economy under the Ramsey optimal monetary policy and show that it features a positive inflation rate. 


\subsection{Model}

\subsubsection{Households}

In every period $j$, a new cohort is born with mass $\gamma$, and each cohort has a constant probability of dying $\gamma$, which does not depend on $j$. The budget constraint for members of cohort $j$ is given by

$$
C_{j, t}+\int_{0}^{1} Q_{t}(i) S_{j, t}(i) d i+\frac{B_{j, t}}{P_{t}\left(1+R_{t}\right)} \leq \frac{1}{1-\gamma}\left[\frac{B_{j, t-1}}{P_{t}}+\int_{0}^{1}\left(Q_{t}(i)+D_{t}(i)\right) S_{j, t-1}(i) d i\right]+\frac{W_{t}}{P_{t}} L_{j, t}
$$

where $S_{j, t}(i)$ is the number of shares issued by firm $i$ and bought by individuals of cohort $j$. These shares offer (real) dividends $D_{t}(i)$, and their real price is $Q_{t}(i) . B_{j, t}$ are bonds that promise a unit of currency tomorrow and cost $\left(1+R_{t}\right)^{-1}$ today. As in Blanchard (1985), households enter an annuity contract in which the fraction $\gamma$ of cohort members dying in each period leaves its wealth to those remaining alive. $C_{j, t}$ and $L_{j, t}$ are consumption and labor supply for cohort $j ; W_{t}$ and $P_{t}$ are nominal wages and the price level in period $t$. The expected lifetime utility for an individual of cohort $j$ is

$$
E_{j} \sum_{t=j}^{\infty}(\beta(1-\gamma))^{t-j}\left[\log \left(C_{j, t}\right)+\chi \log \left(1-L_{j, t}\right)\right]
$$

where $\beta$ is the subjective discount factor of households. The future is discounted at the rate $\beta(1-\gamma)$ to take into account the probability of dying. The first-order conditions for an optimum include the budget constraint (15) holding with equality as well as two intertemporal conditions for shares and bonds and an intratemporal condition for the optimal choice of consumption and hours worked

$$
\begin{gathered}
Q_{t}(i)=\beta E_{t} \frac{C_{j, t}}{C_{j, t+1}}\left(Q_{t+1}(i)+D_{t+1}(i)\right) \\
\beta E_{t} \frac{C_{j, t}}{C_{j, t+1}} \frac{1+R_{t}}{\Pi_{t+1}}=1 \\
\chi \frac{C_{j, t}}{1-L_{j, t}}=\frac{W_{t}}{P_{t}}=w_{t}
\end{gathered}
$$


where $\Pi_{t}=\frac{P_{t}}{P_{t-1}}$ is the gross inflation rate between periods $t-1$ and $t$. The stochastic discount factor between $t$ and $t+1$, conditional on surviving, is

$$
\beta_{t, t+1}=\beta \frac{C_{j, t}}{C_{j, t+1}}
$$

This discount factor is common to all cohorts as can be seen from equation (18). Following Piergallini (2006), Castelnuovo and Nisticò (2010), and Nisticò (2012), one can derive from these equations a policy function for consumption

$$
C_{j, t}=\frac{1-\beta(1-\gamma)}{1+\chi}\left[\Omega_{j, t}+E_{t} \sum_{s=0}^{\infty} \beta_{t, t+s}(1-\gamma)^{s} w_{t+s}\right]
$$

where $\Omega_{j, t}=\frac{1}{1-\gamma}\left(\frac{B_{j, t-1}}{P_{t}}+\int_{0}^{1}\left(Q_{t}(i)+D_{t}(i)\right) S_{j, t-1}(i) d i\right)$ is financial wealth held by cohort $j$ at the beginning of period $t$. Households of each cohort consume out of financial and human wealth with propensity $\frac{1-\beta(1-\gamma)}{1+\chi}$, where human wealth is equal to the discounted sum of expected future labor income.

\section{Aggregation}

Consider any variable $X_{j, t}$ for a cohort born at time $j$ and define the aggregate variable

$$
X_{t} \equiv \sum_{j=-\infty}^{t} \gamma(1-\gamma)^{t-j} X_{j, t}
$$

$X_{t}$ is a weighted average of the individual $X_{j, t}$, where the weights are given by the mass of each cohort $\gamma(1-\gamma)^{t-j}$. The aggregation of the labor supply condition (19) and of the policy function for consumption (21) implies

$$
\begin{gathered}
\frac{\chi C_{t}}{1-L_{t}}=w_{t} \\
C_{t}=\frac{1-\beta(1-\gamma)}{1+\chi}\left[\Omega_{t}+E_{t} \sum_{s=0}^{\infty} \beta_{t, t+s}(1-\gamma)^{s} w_{t+s}\right]
\end{gathered}
$$

Aggregating equation (20) gives

$$
E_{t} \beta_{t, t+1}\left(\frac{C_{t+1}}{1-\gamma}-\frac{\gamma}{1-\gamma} C_{t+1, t+1}\right)=\beta C_{t}
$$


Since new cohorts are born with zero financial wealth, we have that

$$
C_{t, t}=\frac{1-\beta(1-\gamma)}{1+\chi}\left[E_{t} \sum_{s=0}^{\infty} \beta_{t, t+s}(1-\gamma)^{s} w_{t+s}\right]
$$

Using equation (24), this implies

$$
C_{t+1, t+1}=C_{t+1}-\frac{1-\beta(1-\gamma)}{1+\chi} \Omega_{t+1}
$$

Substituting this expression back in (25), we finally obtain

$$
C_{t}=\frac{1}{\beta} E_{t} \beta_{t, t+1} C_{t+1}+\frac{\gamma}{1-\gamma} \frac{1-\beta(1-\gamma)}{\beta(1+\chi)} E_{t} \beta_{t, t+1} \Omega_{t+1}
$$

When $\gamma=0$, we have the familiar Euler equation of the representative agent case. When $\gamma \neq 0$, a wedge related to financial wealth $\Omega_{t+1}$ appears. Indeed, while standard Euler equations hold at the cohort level - see equation (18) - this is no longer true in the aggregate. Expected consumption is not only related to current consumption, interest rates, and expected inflation since 1) a proportion $(1-\gamma)$ of agents in each cohort will die between $t$ and $t+1$ and 2) new agents will appear in $t+1$ for which past Euler equations do not hold. Since these new households are born without any financial wealth, their $t+1$ consumption is lower than the consumption of surviving households by a factor depending on the amount of financial wealth held by the latter. This explains the presence of the $\Omega_{t+1}$ term in equation (28).

\subsubsection{Firms}

Firms produce according to the technology $Y_{t}(i)=Z_{t} L_{t}(i)$ and face quadratic price adjustment costs $\Phi_{t}(i)=\frac{\phi^{p}}{2}\left(\frac{P_{t}(i)}{P_{t-1}(i)}-1\right)^{2} Y_{t}$. These costs have the same composition as the aggregate consumption basket and are proportional to aggregate output. Since firms belong to households, they use the household stochastic discount factor when evaluating future profit flows. They choose $P_{t+s}(i)$ to maximize

$$
E_{t} \sum_{s=0}^{\infty} \beta_{t, t+s}\left[\frac{P_{t+s}(i)}{P_{t+s}} Y_{t+s}(i)-w_{t+s} L_{t+s}(i)-\frac{\phi^{p}}{2}\left(\frac{P_{t+s}(i)}{P_{t+s-1}(i)}-1\right){ }^{2} Y_{t+s}\right]
$$

subject to $Y_{t+s}(i)=Z_{t+s} L_{t+s}(i)$ and $Y_{t+s}(i)=\left(\frac{P_{t+s}(i)}{P_{t+s}}\right)^{-\theta} Y_{t+s}^{D}$, where $Y^{D}$ is aggregate demand. In equilibrium, all firms choose the same price. We obtain a nonlinear Phillips curve relating marginal 
cost to inflation

$$
1-\theta+\theta \frac{w_{t}}{Z_{t}}-\phi^{p} \Pi_{t}\left(\Pi_{t}-1\right)+E_{t} \beta_{t, t+1} \phi^{p} \Pi_{t+1}\left(\Pi_{t+1}-1\right) \frac{Z_{t+1} L_{t+1}}{Z_{t} L_{t}}=0
$$

\subsubsection{Resource constraint}

We normalize the number of shares to one. Aggregate dividends are given by

$$
D_{t}=\int_{0}^{1} D_{t}(i) S_{t-1}(i) d i=Y_{t}-w_{t} L_{t}-\frac{\phi^{p}}{2}\left(\Pi_{t}-1\right)^{2} Y_{t}
$$

Moreover, there is zero net supply of bonds in equilibrium $\left(B_{t}=0\right)$. After aggregating the budget constraints of households and substituting the expression for dividends, we obtain

$$
C_{t}=Z_{t} L_{t}\left[1-\frac{\phi^{p}}{2}\left(\Pi_{t}-1\right)^{2}\right]
$$

\subsubsection{Equilibrium conditions}

A competitive equilibrium is a set of plans $\left\{w_{t}, C_{t}, L_{t}, \Pi_{t}, \beta_{t, t+1}, Q_{t}, \Omega_{t}, R_{t}\right\}$ satisfying the aggregate labor supply condition (23), the aggregate Euler equation (28), the Phillips curve (29), the aggregate resource constraint (31), as well as the following equations

$$
\begin{gathered}
Q_{t}=E_{t} \beta_{t, t+1}\left(Q_{t+1}+Z_{t+1} L_{t+1}\left(1-\frac{\phi^{p}}{2}\left(\Pi_{t+1}-1\right)^{2}\right)-w_{t+1} L_{t+1}\right) \\
\Omega_{t}=Q_{t}+Z_{t} L_{t}\left(1-\frac{\phi^{p}}{2}\left(\Pi_{t}-1\right)^{2}\right)-w_{t} L_{t} \\
E_{t} \frac{R_{t}}{\Pi_{t+1}} \beta_{t, t+1}=1
\end{gathered}
$$

given specifications for the exogenous process $Z_{t}$ and monetary policy $R_{t}$ and where $Q_{t}=\int_{0}^{1} Q_{t}(i) d i$. Equation (32) is obtained by integrating equation (17) over the continuum of firms and substituting the expression for dividends (30). Similarly, equation (33) is obtained by aggregating cohort-specific wealth levels and substituting the expression for dividends (30). Equation (34) simply defines the household stochastic discount factor as the inverse of the real interest rate. Given these aggregate 
dynamics, cohort-specific consumption levels are given by equation (21) and

$$
\Omega_{j, t}=\frac{\Omega_{j, t-1}+w_{t-1}-C_{j, t-1}(1+\chi)}{\beta_{t-1, t}(1-\gamma)}
$$

where $\Omega_{j, j}=0$. Cohort-specific labor supply decisions are then given by equation (19).

\subsubsection{Inflation and steady state outcomes}

I now analyze the effects of inflation on steady-state outcomes. I first consider aggregate variables, notably the wage and the real interest rate. The Phillips curve gives

$$
w=\frac{\theta-1}{\theta}+\frac{\phi^{p}}{\theta} \Pi(\Pi-1)(1-\tilde{\beta})
$$

where $\tilde{\beta}$ is the steady-state value of the stochastic discount factor. For a given level of the real interest rate (or equivalently, of the stochastic discount factor), the wage is clearly increasing in the level of inflation. Because of the presence of discounting in the Phillips curve, an increase in the inflation rate is associated with a decline in markups and an increase in marginal costs which, in steady state, are equal to wages. The aggregate Euler equation can be used to obtain an expression for the stochastic discount factor

$$
\tilde{\beta}=\beta\left[1+\frac{\gamma}{(1-\gamma)} \frac{(1-\beta(1-\gamma))}{(1+\chi)} \frac{\Omega}{C}\right]^{-1}
$$

Two different cases arise. When $\tilde{\beta}=\beta$, households have no incentive to save, and aggregate wealth $\Omega$ is equal to zero. In this situation, all cohorts consumption and labor supply decisions are identical, and the dynamics of the economy are similar to that of the standard New Keynesian model. When $\tilde{\beta}<\beta$, the real interest rate is larger than the household discount rate, and households save a part of their income in equilibrium. As a result, households accumulate wealth over their lifetime and cohorts differ in their consumption and labor supply choices. I will focus on this second case in the rest of the analysis. In that situation, the steady-state real interest rate is not invariant to inflation. Indeed, inflation erodes markups, which causes labor demand to expand and hours worked to increase, and leads to larger costs of adjusting prices, which causes dividends and wealth to fall. Aggregate consumption is a hump-shaped function of inflation; at low inflation rates, the increase in hours worked dominates the increase in adjustment costs and consumption increases; at higher inflation rates, the reverse happens. In the numerical applications considered in this paper, wealth always declines faster than 
consumption, and the ratio $\frac{\Omega}{C}$ declines with inflation. This implies that the steady-state real interest rate is a decreasing function of the inflation rate. However, this effect is quantitatively very small.

Through aggregate variables, inflation has an effect on the distribution of consumption and hours worked across cohorts. Consider the case of newly born households of age zero. Their steady-state consumption level moves with inflation according to

$$
\frac{\partial C_{0}}{\partial \Pi}=\frac{1-\beta(1-\gamma)}{1+\chi}\left[\frac{\frac{\partial w}{\partial \Pi}(1-\tilde{\beta}(1-\gamma))+\frac{\partial \tilde{\beta}}{\partial \Pi} w(1-\gamma)}{(1-\tilde{\beta}(1-\gamma))^{2}}\right]
$$

which is unambiguously positive given that $\frac{\partial w}{\partial \Pi}>0$ and $\frac{\partial \tilde{\beta}}{\partial \Pi}>0$. Households of age zero consume a given fraction of their permanent labor income. The latter increases with inflation both because wages increase and because future labor income is discounted less heavily. After using the individual Euler equations of households to express consumption of age $h$ cohorts as a function of $C_{0}$, we can similarly derive the effect of inflation on the steady-state consumption level of age $h$ cohorts

$$
\frac{\partial C_{h}}{\partial \Pi}=\left(\frac{\beta}{\tilde{\beta}}\right)^{h}\left(\frac{\partial C_{0}}{\partial \Pi}-\frac{\partial \tilde{\beta}}{\partial \Pi} h \frac{C_{0}}{\tilde{\beta}}\right)
$$

Given that $\frac{\partial \tilde{\beta}}{\partial \Pi}$ is small, $\frac{\partial C_{h}}{\partial \Pi}$ is initially positive. However, as $h$ increases, the second term starts to dominate, and $\frac{\partial C_{h}}{\partial \Pi}$ turns negative. This second effect comes from the fact that inflation reduces the return to savings and the financial wealth of households. The older households are, the larger the decrease in financial wealth. At a certain threshold $\bar{h}$, this decrease becomes larger than the increase in permanent labor income captured by the term $\frac{\partial C_{0}}{\partial \Pi}$. Since the propensity to consume out of financial wealth and labor income is identical, it follows that the consumption of cohorts $h \geq \bar{h}$ declines with inflation. Inflation thus redistributes consumption away from old households and towards young households.

Note that, just as in the standard New Keynesian model of section 2, the effects of inflation on real outcomes operate through markups and the deadweight cost of adjusting prices. However, because of the heterogeneity among households, movements in these two variables have more widespread consequences in this framework. 


\subsection{The optimal long-run inflation rate}

I now solve for the optimal inflation rate. In order to do so, I first spend some time discussing how the planner aggregates the utilities of different generations in section 3.2.1. This sheds some light on the distortions arising in the decentralized equilibrium that can be partially offset through inflation. In section 3.2.2, I solve analytically for the steady state of the economy under the Ramsey optimal monetary policy. Section 3.2.3 provides a numerical application.

\subsubsection{Welfare and the optimal allocation}

I denote by $\xi$ the social discount factor according to which the planner discounts generations. In this overlapping generation context, the planner's objective is the sum of two components. The first is the expected lifetime utilities of generations that are yet to be born. The second is the sum of expected flow utilities, over the remainder of their lifetimes, of existing generations. As demonstrated by Calvo and Obstfeld (1988), in order for the optimal allocation to give rise to time-consistent consumption plans, the expected utilities of each generation needs to be discounted from the perspective of their birth date. This implies that social welfare at time $0, W_{0}$, is equal to

$$
\begin{aligned}
& W_{0}=E_{0} \sum_{j=1}^{\infty} \xi^{j} \sum_{t=j}^{\infty} \gamma(\beta(1-\gamma))^{t-j}\left(\log \left(C_{j, t}\right)+\chi \log \left(1-L_{j, t}\right)\right) \\
& +E_{0} \sum_{j=-\infty}^{0} \xi^{j} \sum_{t=0}^{\infty} \gamma(\beta(1-\gamma))^{t-j}\left(\log \left(C_{j, t}\right)+\chi \log \left(1-L_{j, t}\right)\right)
\end{aligned}
$$

where the first term is the expected lifetime utilities of future generations, and the second term is the appropriately discounted expected sum of future utilities flows of existing generations. This equation makes clear that the planner cares about the lifetime utility of each cohort. When $\xi=1$, generations are treated equally, and the instantaneous utility flow of an individual of age $h$ is discounted similarly regardless of the current date. When $\xi<1$, the lifetime utility of older cohorts is weighted more heavily in the objective function, a practice Ramsey (1928) would have deemed to be "ethically indefensible". Equation (37) can be reformulated in a more compact way by changing the order of summation

$$
W_{0}=E_{0}\left\{\sum_{t=0}^{\infty} \xi^{t} \sum_{j=-\infty}^{t} \gamma\left(\frac{\beta(1-\gamma)}{\xi}\right)^{t-j}\left(\log \left(C_{j, t}\right)+\chi \log \left(1-L_{j, t}\right)\right)\right\}
$$


We are now in a position to derive the first-best allocation. The planner chooses $C_{j, t}$ and $L_{j, t}$ in order to maximize (38) subject to the aggregate resource constraint

$$
\sum_{j=-\infty}^{t} \gamma(1-\gamma)^{t-j} C_{j, t}=Z_{t}\left(\sum_{j=-\infty}^{t} \gamma(1-\gamma)^{t-j} L_{j, t}\right)
$$

The first-order conditions imply

$$
\begin{gathered}
\frac{\chi C_{j, t}}{1-L_{j, t}}=Z_{t} \\
\frac{1}{C_{j, t}}=\frac{\beta}{\xi} \frac{1}{C_{j-1, t}}
\end{gathered}
$$

A comparison of a steady-state version of these conditions with the ones arising in the decentralized equilibrium sheds light on the inefficiencies that the monetary authority can attempt to correct for through inflation. First, a static distortion arises from the presence of monopolistic competition. This can be seen by comparing equation (19) with equation (40). In a zero-inflation steady state, $w=\frac{\theta-1}{\theta}$. Monopolistic competition introduces a wedge between the marginal rate of substitution between consumption and leisure, equal to $\frac{\chi C_{j}}{1-L_{j}}$, and the marginal productivity of labor, equal to 1. Since $w$ is an increasing function of steady-state inflation, the monetary authority can partially correct for this distortion by increasing the inflation target. Second, another distortion arises from the distribution of consumption across cohorts. This can be seen by comparing the steady-state versions of equations (20) and (41). In steady state, all agents make similar decisions at the same age, and these equations can be written respectively as $\frac{\beta}{\tilde{\beta}} \frac{C_{h}}{C_{h+1}}=1$ and $\frac{\beta}{\xi} \frac{C_{h}}{C_{h+1}}=1$, where $h$ is age. In the decentralized equilibrium, since the real interest rate is larger than the subjective rate of time preference, agents choose an increasing profile for consumption over their lifetime. Whether this is optimal or not depends on the exact value of $\xi^{2}$. As long as $\xi>\tilde{\beta}$, young individuals consume too little compared to older ones in the decentralized equilibrium. As shown before, an increase in steady-state inflation can partially offset this distortion as it boosts labor income, on which the young disproportionately rely, and depresses capital income, which is the main source of income for older cohorts. These benefits have to be balanced with the deadweight costs of adjusting prices, which reduce the share of output

\footnotetext{
${ }^{2}$ When $\xi=1$, a decreasing age-consumption profile is optimal as utility flows experienced when young enter with a greater weight in lifetime utility. Such a decreasing consumption profile is also optimal for $\xi>\beta$. This conclusion is reversed whenever $\xi<\beta$. While private agents still exhibit a preference for the present, the planner now puts a larger relative weight on older generations. As a consequence, allocating more consumption to older generations becomes optimal.
} 
available for consumption, as can be seen in equation (31).

\subsubsection{Ramsey optimal monetary policy}

The central bank chooses a path $\left\{R_{t}\right\}_{t=0}^{\infty}$ to maximize social welfare (38) subject to the constraints of the competitive economy. These constraints can be subdivided in three parts. A first set of constraints describes the evolution of aggregate variables; the Phillips curve (29), and the definition of dividends $(30)^{3}$. A second set of constraints describes the evolution of cohort-specific variables; the Euler equations for shares (17) and bonds (18), the intratemporal conditions for the optimal choice of consumption and hours worked (19), and the individual budget constraints (15) holding with equality. Each of these equations is cohort-specific and therefore appears $j$ times. A third set of constraints consists of the bridge equations between aggregate and cohort-specific variables and is given in generic form by $X_{t}=\sum_{j=-\infty}^{t} \gamma(1-\gamma)^{t-j} X_{j, t}$.

In order to be able to solve this problem, I now simplify it in several ways. This procedure is described in detail in appendix 2. First, as in section 2, the problem can be seen as one in which the central bank directly chooses the allocation. Once the paths for the stochastic discount factor and inflation are known, the Euler equation for bonds can be used to back out the path of nominal interest rates consistent with this allocation. Second, the system is consolidated through repeated substitutions and by getting rid of all cohort-specific constraints and variables. In the end, the Ramsey planner chooses the sequence $\left\{C_{t}, \Pi_{t}, w_{t}, \beta_{t, t+1}\right\}_{t=0}^{\infty}$ to maximize the following Lagrangian

$$
\begin{gathered}
L=\sum_{t=0}^{\infty} \xi^{t}\left(-\frac{\chi \gamma}{1-\frac{\beta(1-\gamma)}{\xi}} \log \left(w_{t}\right)+(1+\chi) \sum_{j=-\infty}^{t} \gamma\left(\frac{\beta(1-\gamma)}{\xi}\right)^{t-j}\left[\log \left(w_{j}+\sum_{h=1}^{\infty} \beta_{j, j+h}(1-\gamma)^{h} w_{j+h}\right)-\log \left(\beta_{j, t}\right)\right]\right. \\
+\lambda_{1 t}\left[\frac{\theta-1}{\theta}+\frac{\phi^{p}}{\theta} \Pi_{t}\left(\Pi_{t}-1\right)-\beta_{t, t+1} \frac{\phi^{p}}{\theta} \Pi_{t+1}\left(\Pi_{t+1}-1\right) \frac{1-\frac{\chi}{w_{t+1}} C_{t+1}}{1-\frac{\chi}{w_{t}} C_{t}}-w_{t}\right] \\
+\lambda_{2 t}\left[\left(1-\frac{\phi^{p}}{2}\left(\Pi_{t}-1\right)^{2}\right)\left(1-\frac{\chi}{w_{t}} C_{t}\right)-C_{t}\right] \\
\left.+\lambda_{3 t}\left[\sum_{j=-\infty}^{t} \gamma(1-\gamma)^{t-j} \frac{\beta^{t-j}}{\beta_{j, t}}\left(w_{j}+\sum_{h=1}^{\infty} \beta_{j, j+h}(1-\gamma)^{h} w_{j+h}\right)-\frac{1+\chi}{1-\beta(1-\gamma)} C_{t}\right]\right)
\end{gathered}
$$

\footnotetext{
${ }^{3}$ The other aggregate equilibrium conditions listed in section 3.1.4 are not directly included but appear implicitly through the cohort-specific conditions and the bridge equations between aggregate and cohort-specific variables.
} 
where $\lambda_{1 t}, \lambda_{2 t}$ and $\lambda_{3 t}$ are the Lagrange multipliers associated with the three constraints. I assume that the current policy has been in place for a long time or, in other words, that monetary policy is conducted from a timeless perspective (Woodford 2003). I therefore compute first-order conditions in $t=t_{1}$, where $t_{1}$ is arbitrarly large, and ignore the transition path from time 0 to time $t_{1}$. Furthermore, I abstract from uncertainty in the analysis and, for ease of notation, drop expectation operators. While the infinite sums over all generations introduce some complications when computing the first-order conditions, they also have a side benefit. By using formulas for infinite geometric series, one can derive analytical expressions for the steady-state version of these first-order conditions provided that some restrictions on $\tilde{\beta}, \beta, \xi$ and $\gamma$ are verified. These derivations are presented in appendix 2 , where I also prove the following result analytically.

Proposition: In a model with monopolistic competition, quadratic price adjustment costs, and a perpetual youth structure, optimal inflation in the Ramsey equilibrium is different from zero in steady state unless the social discount factor coincides with the steady-state value of the discount factor used by firms when evaluating future profit flows.

The first-order condition with respect to inflation bears some similarities with the simple formula for the optimal inflation rate derived in section 2 . In steady state, it is equal to

$$
\lambda_{1} \frac{\phi^{p}}{\theta}(2 \Pi-1)\left(1-\frac{\tilde{\beta}}{\xi}\right)-\lambda_{2} \phi^{p}(\Pi-1) L=0
$$

The first term is the marginal benefits of inflation. The multiplier $\lambda_{1}$ captures the effect of movements in marginal costs on social welfare, and $\frac{\phi^{p}}{\theta}(2 \Pi-1)(1-\tilde{\beta} / \xi)$ is the discounted effect of inflation on marginal costs. The second term is the marginal costs of inflation. The multiplier $\lambda_{2}$ captures the effect of movements in aggregate consumption on social welfare, and $-\phi^{p}(\Pi-1) L$ is the effect of an increase in inflation on aggregate consumption operating through the costs of price adjustment ${ }^{4}$. The precise values of $\lambda_{1}$ and $\lambda_{2}$ depend on $\Pi$ and on the structure of the economy, notably the extent of household heterogeneity. For inflation to be optimal, marginal costs and benefits have to be equal. There are two particular situations in which this happens for a net inflation rate of zero- that is, for

\footnotetext{
${ }^{4}$ The term $\frac{\phi^{p}}{\theta}(2 \Pi-1)(1-\tilde{\beta} / \xi)$ is computed by holding other variables in the Phillips curve fixed. Inflation may also have an indirect effect on marginal costs through these variables. Similarly, $-\phi^{p}(\Pi-1) L$ is computed by holding $L$ fixed. Inflation also influences aggregate consumption indirectly through $L$. These indirect effects are captured by the multipliers $\lambda_{1}$ and $\lambda_{2}$. This, of course, has the disadvantage of making equation (42) less clear-cut to interpret than equation (9).
} 
$\Pi=1$. In the first case, the elasticity of substitution between goods $\theta$ tends toward infinity. Although the steady state is not efficient ( $\tilde{\beta}$ tends toward $\beta$ but $\xi$ may still differ from $\beta$ ), the monetary authority loses its leverage over markups, and the marginal benefits of inflation tend toward zero. In the second case, $\theta$ is finite and $\xi$ is equal to $\tilde{\beta}$. The effects of inflation on markups are dynamic, and the planner weights them according to their distance in the future. When $\xi$ is equal to $\tilde{\beta}$, this weighting scheme offsets exactly the effect of inflation on average markups. In both cases, since a positive inflation target does not bring any benefits, the central bank chooses an optimal inflation rate of zero in order to minimize the deadweight costs associated with price adjustments.

In practice, no specific criterion calls for the social discount factor to be exactly equal to the stochastic discount factor prevailing in the zero-inflation steady state. Thus, in the presence of monopolistic competition, the optimal inflation rate will generally be different from zero. The following section considers a baseline calibrated version of the model and solves for numerical values of the optimal inflation rate as a function of key parameters.

\subsubsection{Numerical analysis}

The elasticity of substitution between goods $\theta$ is set equal to 6 , which implies a markup of 20 percent in the zero-inflation steady state. The price adjustment cost parameter $\phi^{p}$ is chosen according to the following logic. The linearized Phillips curve of the model is observationally equivalent to the one derived under Calvo pricing, and structural estimates of New Keynesian models find an elasticity of inflation with respect to marginal cost $\omega$ of 0.5 (Lubik and Schorfheide 2004). In my model, $\omega=\frac{\theta-1}{\phi^{p}}$, which implies that $\phi^{p}=10$. Alternatively, assuming an average contract duration of 4 quarters, the coefficient $\omega$ under Calvo pricing would be equal to 0.0846 . This implies $\phi^{p}=59$. I choose an intermediate value $\phi^{p}=40$. I also experiment with other values as a robustness check. The household discount factor $\beta$ is fixed at 0.995 . The key parameter driving a wedge between $\beta$ and the steady-state stochastic discount factor is the turnover rate $\gamma$. If one interprets the model literally, $\gamma$ represents an average probability of dying for individuals, which is likely to be very low at a quarterly frequency. Alternatively, one can see the perpetual youth model as capturing transitions in and out of hand-to-mouth status and other forms of wealth resetting such as household default. Following this interpretation, Del Negro et al. (2015) use values of $\gamma$ ranging from 0.03 to 0.06 . In the model of Castelnuovo and Nisticò (2010), this turnover rate is estimated to be much higher at about 0.13. For $\beta<1$, such high values for $\gamma$ imply implausibly large values for the steady-state real interest rate. I 
thus choose the lowest value considered in the literature, $\gamma=0.03$, which corresponds to a steady-state real interest rate of 4.5 percent. Finally, the Frisch elasticity of labor supply depends on the level of hours worked $L_{t}$. I calibrate $\chi$ so that it is equal to 2 in a zero-inflation steady state. This implies that steady-state hours are equal to $1 / 3$.

Figure 3 plots the annualized optimal inflation rate as a function of the social discount factor $\xi$. When the central bank evaluates the lifetime utilities of different generations according to the household discount factor, the deviations from price stability are modest with an optimal inflation rate of 0.8 percent. As the relative weight on old generations decreases - that is, as $\xi$ increases - the optimal inflation rate increases. This happens for two reasons. First, the discounted effect of inflation on marginal costs becomes larger as the gap between $\xi$ and $\tilde{\beta}$ increases. Second, since an increase in marginal cost redistributes consumption from the old to the young, raising the inflation target becomes more interesting as the weight on young generations in social welfare increases $-\lambda_{1}$ in equation (42) increases. When the monetary authority treats all generations equally, following Ramsey's (1928) suggestion, the optimal inflation rate reaches 3.2 percent. Inversely, for lower values of $\xi$, the optimal inflation rate is closer to zero both because the gap between $\xi$ and $\tilde{\beta}$ shrinks and because using inflation to erode markups becomes less beneficial as the relative weight on young generations decreases. When $\xi=\tilde{\beta}$, long-run price stability is optimal.

I now adopt $\xi=1$ as my baseline calibration and study the robustness of the results to two parameters, the degree of price stickiness $\phi^{p}$ and the elasticity of substitution between goods $\theta$. Figure 4 shows that the optimal inflation rate is to a large extent independent of the degree of price stickiness. The rationale for this result is as follows. An increase in $\phi^{p}$ has two opposing effects. On the one hand, it gives monetary policy more leverage over markups, thereby raising the marginal benefits of inflation. On the other hand, it increases the deadweight cost of adjusting prices for a given level of inflation, thereby raising the marginal costs of inflation. These two effects broadly seem to offset each other. Figure 5 shows that the optimal inflation rate is a decreasing function of the elasticity of substitution between goods. A higher $\theta$ is associated with a lower steady state markup and a weaker relationship between inflation and wages, as can be seen from equation (35). Thus, the marginal benefits of inflation decrease with $\theta$, and consequently, so does the optimal inflation target. 


\section{Two examples from the existing macroeconomic literature}

The preceding section provided a novel application of the general property outlined in section 2 . This section shows that this property is also relevant to understand some existing results in the literature. As demonstrated analytically in the appendix, in models with firm entry and exit or in environments with labor market frictions and costly nominal wage adjustment, the optimality of a non-zero inflation rate arises from differences in the way profit and utility flows are discounted.

\subsection{Firm entry and exit}

Bilbiie et al. (2014) study optimal monetary policy in a sticky-price model with endogenous firm entry and product variety and find that deviations from long-run price stability are generally desirable. In the model, each firm produces a different good, and consumers exhibit a taste for good variety. Firm entry takes place subject to sunk costs in the expectations of future monopoly profits, and the presence of imperfect price adjustment gives rise to a Phillips curve relating markups to inflation. The central bank can therefore use its leverage over markups to manipulate entry and align the number of varieties with the benefits of variety to consumers. When those benefits fall short of the incentives to create new varieties, the monetary authority engineers positive inflation to reduce markups and firm entry. When the number of varieties is too low, the monetary authority creates deflation in order to increase markups and the incentives to create new varieties. In this environment, firms exit the market with exogenous probability $\delta$ in each period. Consequently, the effective discount factor appearing in the Phillips curve in steady state differs from the household discount factor by a factor $1-\delta$ depending on this mortality rate. Appendix 3 derives the Ramsey problem faced by the monetary authority for an arbitrary value of the social discount factor $\xi$ (which may therefore differ from the household discount factor $\beta$ ) and shows that discount factor heterogeneity is key in generating deviations from long-run price stability. In Bilbiie et al., $\xi=\beta$, and the long-run optimal inflation rate is different from zero unless the steady state is efficient. They argue that a plausible calibration of the model justifies an optimal inflation target of 2 percent or higher. In the appendix, I show that when $\xi=\beta(1-\delta)$ - that is, when the social discount factor is equal to steady state effective discount factor used by firms when evaluating profit flows - optimal long-run inflation is equal to zero regardless of the degree of steady-state inefficiency. The logic behind this result is similar as in section 2 . In the model, the effects of inflation on markups are dynamic. Higher inflation at time $t$ reduces markups and entry at time $t$ but increases markups and entry before time $t$, insofar as it is expected in advance. These 
consequences happening in different periods are assigned a different weight by the Ramsey planner. When $\xi=\beta(1-\delta)$, this social weighting effect perfectly offsets the effect of inflation on average markups. The discounted effects of inflation on markups are then equal to zero, and the central bank chooses an inflation rate that minimizes the costs of price stickiness.

\subsection{Labor market frictions and nominal wage stickiness}

I have thus far focused on environments with monopolistic competition in the goods market and price stickiness. However, as long as the effects of inflation on markups are dynamic, there is reason to think that the property described in section 2 can apply to cases with imperfect competition and nominal stickiness in other markets. In order to illustrate this, I now consider in appendix 4 a New Keynesian model with search and matching frictions in the labor market and costly nominal wage adjustment. In the model, firms and workers bargain over nominal wages, and firms have to incur costs to adjust nominal wages. In steady state, the bargaining power of workers is too high relative to its efficient level, and job creation is inefficient. Because of labor market turnover, the effective discount factor used during wage negotiations differs from the household stochastic discount factor by a factor depending on the separation probability from employment $\rho$. As already noted by Arseneau and Chugh (2008) in a similar model, this gives monetary policy some leverage over the wage markup. By increasing inflation, the central bank can reduce the bargaining power of workers - that is, reduce the wage markup - and boost job creation. However, as in the other frameworks considered in this paper, the effects of inflation are dynamic. Higher inflation at time $t$ reduces the bargaining power of workers at time $t$ and increases the bargaining power of workers at time $t-1$ through expected inflation. These outcomes are weighted differently by the Ramsey planner. Appendix 4 derives the Ramsey problem faced by the monetary authority. It shows that the optimal long-run inflation rate is equal to zero in the now familiar case where the social discount factor $\xi$ is equal to the steady-state discount factor used by firms and workers in wage negotiations $\beta(1-\rho)$. In that case, the social weighting effect offsets exactly the effect of inflation on the average wage markup. Whenever $\xi>\beta(1-\rho)$, the discounted effect of inflation on the wage markup is positive, and as a result, so is the optimal inflation target. In a baseline calibrated version of the model, which also includes monopolistic competition in the goods market and sticky prices and where $\xi=\beta$, the optimal inflation rate is equal to 1.6 percent in annual terms. Interestingly, this figure rises with the degree of indexation of nominal wages to past inflation. 
Two additional elements are worth emphasizing. First, the presence of labor market frictions is essential to obtaining this result. If the labor market was instead characterized by monopolistic competition and if all labor adjustment took place along the intensive margin, as in for example Erceg et al. (2000), the optimal inflation rate would be equal to zero. In that case, the effective discount factor appearing in the wage Phillips curve in steady state does not differ from the household discount factor. Second, Carlsson and Westermark (2016) similarly argue that the interaction of labor market frictions and nominal wage stickiness generates an optimal inflation rate that is significantly positive. However, the mechanism through which this happens is different. In their paper, nominal wages are renegotiated infrequently, and newly hired workers join the existing nominal wage structure within the firm. By increasing the inflation target, the central bank can therefore decrease their real wages and boost job creation. This channels disappears if newly hired workers negotiate wages at the time of being hired. On the contrary, in the model developed in the appendix, the optimal long-run inflation rate is positive even though bargaining takes places in every period. Thus, regardless of how one interprets the mixed evidence about the flexibility of the wages of new hires (see for example Haefke et al. 2013, Stüber 2017, or Gertler et al. 2018), the combination of labor market frictions and nominal wage stickiness seems to justify the adoption of positive inflation targets.

\section{Conclusion}

A large literature seeks to describe optimal monetary policy in dynamic economies featuring nominal and real rigidities. A conclusion emerging from this literature is that the presence of price stickiness calls for a zero long-run inflation rate. This paper challenges this conclusion. It argues that the optimal inflation rate can be significantly positive when profits flows are discounted more heavily than utility flows and illustrates this by studying optimal monetary policy in several environments in which such a property arises.

In sticky-price models, the central bank can lower the long-run level of markups by engineering a positive rate of inflation but incurs resource costs or costs related to price dispersion. This suggests that the inflation rate should be set to a slightly positive value in order to strike a balance between these costs and benefits. However, the problem faced by the monetary authority is intrinsically dynamic. Inflation in a given period $t$ has consequences on markups both in period $t$ and in periods preceding $t$ through anticipated inflation. These real consequences of inflation are weighted differently by the 
central bank, depending on their distance in the future. When social and private discount factors are equal, the weighting effect perfectly offsets the effect of inflation on average markups, and the optimal long-run inflation rate is equal to zero. This is no longer true when social and private discount factors differ. I investigate the quantitative implications of this heterogeneity in three different frameworks. I first consider a New Keynesian model with a perpetual youth structure. In this setting, the social discount rate, which reflects the relative weight the monetary authority places on the lifetime utilities of various generations, need not coincide with the real interest rate, according to which firms discount profit flows. Under the assumption that the planner treats all generations equally, following Ramsey's (1928) suggestion, I find that the optimal inflation rate is significantly positive at 3.2 percent per year, although the gap between social and private discount rates is small. Second, I show that such a heterogeneity in discount factors arises endogenously in models with firm entry and exit and in environments with labor market frictions and another form of nominal rigidity, wage stickiness. In both cases, it provides a rationale for moderately positive inflation targets.

The presence of discount factor heterogeneity may also call for deviations from long-run price stability in other macroeconomic environments. As an example, consider the growing literature that incorporates household heterogeneity in New Keynesian models. In McKay et al. (2016), the presence of uninsurable income risk and borrowing constraints gives rise to precautionary savings which push the real interest rate below the household discount rate. In Kaplan et al. (2018), households can self-insure by saving either in low-return liquid government bonds or high-return illiquid firm shares or capital. This assumption leads to the presence of a sizable fraction of wealthy hand-to-mouth households, as in the data, and implies that profit flows are discounted at a higher rate than utility flows. Finally, another relevant example comes from the literature on financial frictions. In the model of Gilchrist et al. (2017), firms face financial frictions while setting prices in customer markets. In reaction to an adverse shock, they become more myopic in their decision making in order to preserve internal liquidity and avoid accessing external finance. In all those cases, the effects of inflation operating through markups should call for deviations from long-run price stability. At the same time, other frictions present in those models may independently push the optimal inflation target in another direction. Such an analysis is beyond the scope of this paper and is left for future research. 


\section{References}

[1] Adam, Klaus, and Henning Weber (forthcoming). "Optimal Trend Inflation," American Economic Review.

[2] Andrade, Philippe, Jordi Galí, Hervé Le Bihan, and Julien Matheron (2018). "The Optimal Inflation Target and the Natural Rate of Interest," NBER Working Paper Series 24328. Cambridge, Mass.: National Bureau of Economic Research, February, www.nber.org/papers/w24328.

[3] Arseneau, David M., and Sanjay Chugh (2008). "Optimal Fiscal and Monetary Policy with Costly Wage Bargaining," Journal of Monetary Economics, vol. 55(8), pp. 1401-1414.

[4] Banerjee, Anindya, and Bill Russell (2001). "The Relationship between the Markup and Inflation in the G7 Economies and Australia," The Review of Economics and Statistics, vol. 83(2), pp. $377-384$.

[5] Bénabou, Roland J. M. (1992). "Inflation and Markups: Theories and Evidence from the Retail Trade Sector," European Economic Review, vol. 36(2-3), pp. 566-574.

[6] Bilbiie, Florin O., Ippei Fujiwara, and Fabio Ghironi (2014). "Optimal Monetary Policy with Endogenous Entry and Product Variety," Journal of Monetary Economics, vol. 64, pp. 1-20.

[7] Blanchard, Olivier (1985). "Debt, Deficits and Finite Horizons," Journal of Political Economy, vol. 93(2), pp. 223-247.

[8] Blanchard, Olivier, and Jordi Galí (2007). "Real Wage Rigidities and the New Keynesian Model," Journal of Money, Credit, and Banking, vol. 39(1), pp. 35-66.

[9] Calvo, Guillermo. A. (1983). "Staggered Prices in a Utility-maximizing Framework," Journal of Monetary Economics, vol. 12(3), pp. 383-398.

[10] Calvo, Guillermo A., and Maurice Obstfeld (1988). "Optimal Time-Consistent Fiscal Policy with Finite Lifetimes," Econometrica, vol. 56(2), pp. 411-432.

[11] Carlsson, Mikael, and Andreas Westermark (2016). "Labor Market Frictions and Optimal SteadyState Inflation," Journal of Monetary Economics, vol. 78(C), pp. 67-79. 
[12] Castelnuovo, Efrem, and Salvatore Nisticò (2010). "Stock Market Conditions and Monetary Policy in a DSGE Model for the US," Journal of Economic Dynamics and Control, vol 34(9), pp. $1700-1731$.

[13] Coibion, Olivier, Yuriy Gorodnichenko, and Johannes Wieland (2012). "The Optimal Inflation Rate in New Keynesian Models: Should Central Banks Raise Their Inflation Targets in Light of the Zero Lower Bound?" Review of Economic Studies, vol. 79(4), pp. 1371-1406.

[14] Cotton, Christopher D. (2018). "The Inflation Target and the Equilibrium Real Rate," New York, NY: Mimeo, available at www.cdcotton.com/papers/pistar-rstar.pdf.

[15] Del Negro, Marco, Marc Giannoni, and Christina Patterson (2015). "The Forward Guidance Puzzle," Working Paper Series. New York, NY: Federal Reserve Bank of NY, December, www.newyorkfed.org/research/staff_reports/sr574.html.

[16] Diercks, Anthony M., 2017. "The Reader's Guide to Optimal Monetary Policy," Social Science Research Network. Retrieved from: https://ssrn.com/abstract $=2989237$ or http://dx.doi.org/10.2139/ssrn.2989237.

[17] Erceg, Christopher J., Dale W. Henderson, and Andrew T. Levin (2000). "Optimal Monetary Policy with Staggered Wage and Price Contracts," Journal of Monetary Economics, vol 46(2), pp. 281-313.

[18] Furlanetto, Francesco, and Nicolas Groshenny (2016). "Mismatch Shocks and Unemployment during the Great Recession," Journal of Applied Econometrics, vol. 31(7), pp. 1197-1214.

[19] Galí, Jordi (2008). Monetary Policy, Inflation and the Business Cycle: An Introduction to the New Keynesian Framework. Princeton, NJ: Princeton University Press.

[20] Galí, Jordi (2017). "Monetary Policy and Bubbles in a New Keynesian Model with Overlapping Generations," Barcelona, Spain: Centre de Recerca en Economia Internacional.

[21] Gertler, Mark, Christopher Huckfeldt, and Antonella Trigari (2016)." Unemployment Fluctuations, Match Quality and the Wage Cyclicality of New Hires," NBER Working Paper Series 22341. Cambridge, Mass.: National Bureau of Economic Research, June, www.nber.org/papers/w22341.

[22] Gilchrist, Simon, Raphael Schoenle, Jae Sim, and Egon Zakrajsek (2017). "Inflation Dynamics during the Financial Crisis," American Economic Review, vol 107(3), pp. 785-823. 
[23] Goodfriend, Marvin, and Robert King (1997). "The New Neoclassical Synthesis and the Role of Monetary Policy," NBER Macroeconomics Annual 1997, vol. 12, pp. 231-296.

[24] Haefke, Christian, Marcus Sonntag, and Thijs van Rens (2013). "Wage Rigidity and Job Creation," Journal of Monetary Economics, vol. 60(8), pp. 887-899.

[25] Hosios, Arthur J. (1990). "On the Efficiency of Matching and Related Models of Search and Unemployment," Review of Economic Studies, vol. 57(2), pp. 279-98.

[26] Kaplan, Greg, Benjamin Moll, and Giovanni L. Violante (2018). "Monetary Policy According to HANK," American Economic Review, vol. 108(3), pp. 697-743.

[27] King, Robert, and Alexander L. Wolman (1999). "What Should the Monetary Authority Do When Prices Are Sticky?" NBER Macroeconomics Annual 1999, pp. 349-404.

[28] Lepetit, Antoine (2018). Asymmetric Unemployment Fluctuations and Monetary Policy Tradeoffs. Paris, France: Mimeo, available at https://hal.archives-ouvertes.fr/hal-01536416v2/document.

[29] Lubik, Thomas, and Frank Schorfheide (2004). "Testing for Indeterminacy: An Application to U.S. Monetary Policy," American Economic Review, vol. 94(1), pp. 190-217.

[30] McKay, Alisdair, Emi Nakamura, and Jon Steinsson (2016). "The Power of Forward Guidance Revisited," American Economic Review, vol. 106(10), pp. 3133-3158.

[31] Nisticò, Salvatore (2012). "Monetary Policy and Stock-Price Dynamics in a DSGE framework," Journal of Macroeconomics, vol. 34(1), pp. 126-146.

[32] Nisticò, Salvatore (2016). "Optimal Monetary Policy and Financial Stability in a Non-Ricardian Economy," Journal of the European Economic Association, vol. 14(5), pp. 1225-1252.

[33] Petrongolo, Barbara, and Christopher Pissarides (2001). "Looking into the Black Box: a Survey of the Matching Function," Journal of Economic Literature, vol. 39(2), pp. 390-431.

[34] Piergallini, Alessandro (2006). "Real Balance Effects and Monetary Policy," Economic Inquiry, vol. $44(3)$, pp. $497-511$.

[35] Ramsey, Frank P. (1928). "A Mathematical Theory of Saving," Economic Journal, vol. 38(152), pp. $543-559$. 
[36] Rotemberg, Julio J. (1982). "Sticky Prices in the United States," Journal of Political Economy, vol. $90(6)$, pp. 1187-1211.

[37] Schmitt-Grohé, Stephanie, and Martin Uribe (2010). "The Optimal Rate of Inflation," Handbook of Monetary Economics, edition 1, vol. 3, chapter 13, pp. 653-722.

[38] Silva, José I., and Manuel Toledo (2009). "Labor Turnover Costs and the Cyclical Behavior of Vacancies and Unemployment," Macroeconomic Dynamics, vol. 13, pp. 76-96.

[39] Stüber, Heiko (2017). "The Real Wage Cyclicality of Newly Hired and Incumbent Workers in Germany," Economic Journal, vol. 127(600), pp. 522-546.

[40] Summers, Laurence H., David Wessel, and John D. Murray (2018). "Rethinking the Fed's 2 percent inflation target," Washington, D.C.: Brookings Institute.

[41] Woodford, Michael (2003). Interest and Prices; Foundations of a Theory of Monetary Policy. Princeton, NJ: Princeton University Press.

[42] Yaari, Menahem E. (1965). "Uncertain Lifetime, Life Insurance, and the Theory of the Consumer," The Review of Economic Studies, vol. 32(2), pp. 137-150. 


\section{$6 \quad$ Figures}
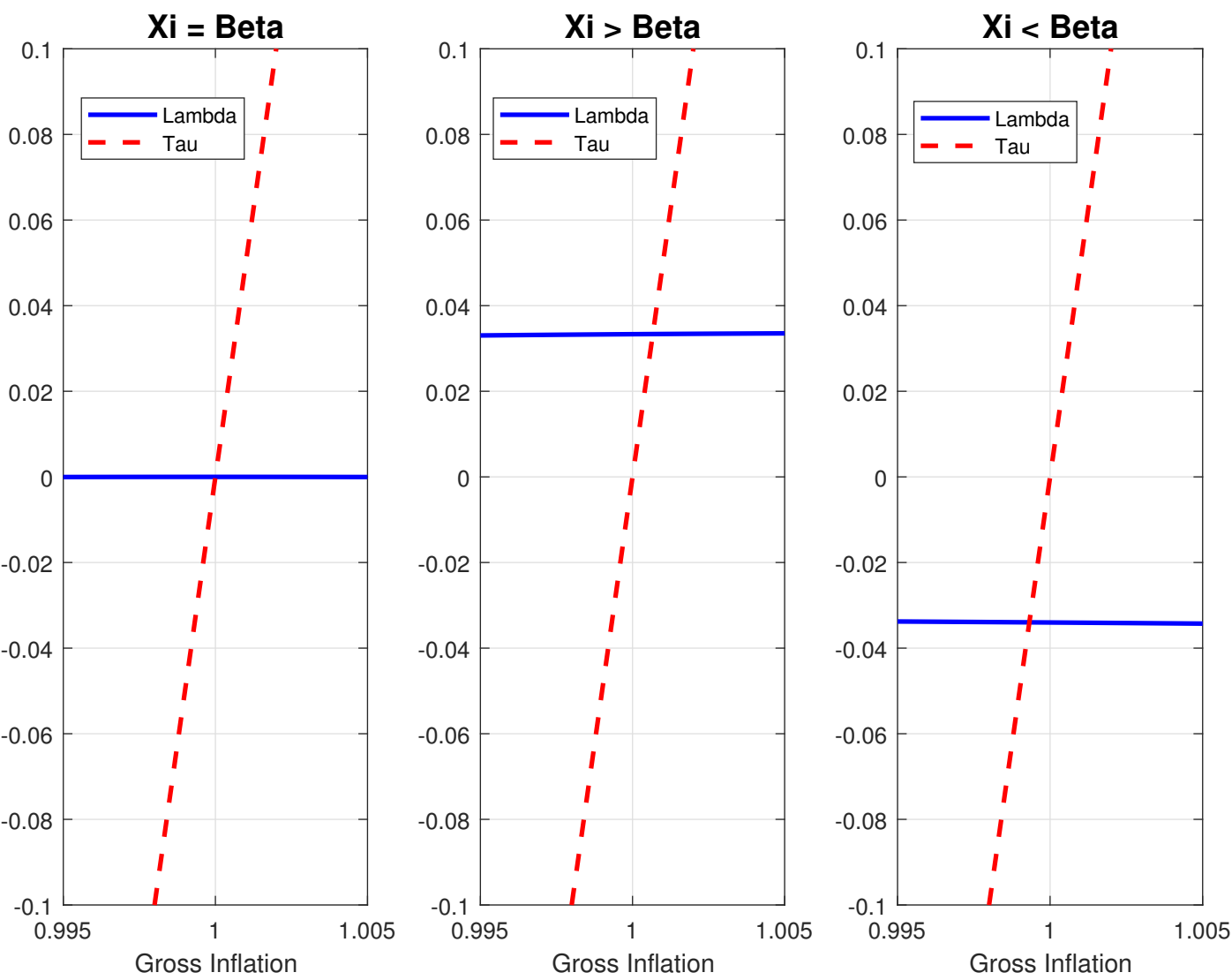

Figure 1: $\Lambda$ and $\Gamma$ according to the value of $\frac{\xi}{\beta}$ with Rotemberg pricing. In the first case, $\xi=\beta=0.99$. In the second case, $\xi=1$ and $\beta=0.99$. In the third case, $\xi=0.98$ and $\beta=0.99$. The other parameters are calibrated as follows: $\phi^{p}=40, \theta=6, \varphi=0.5$. 

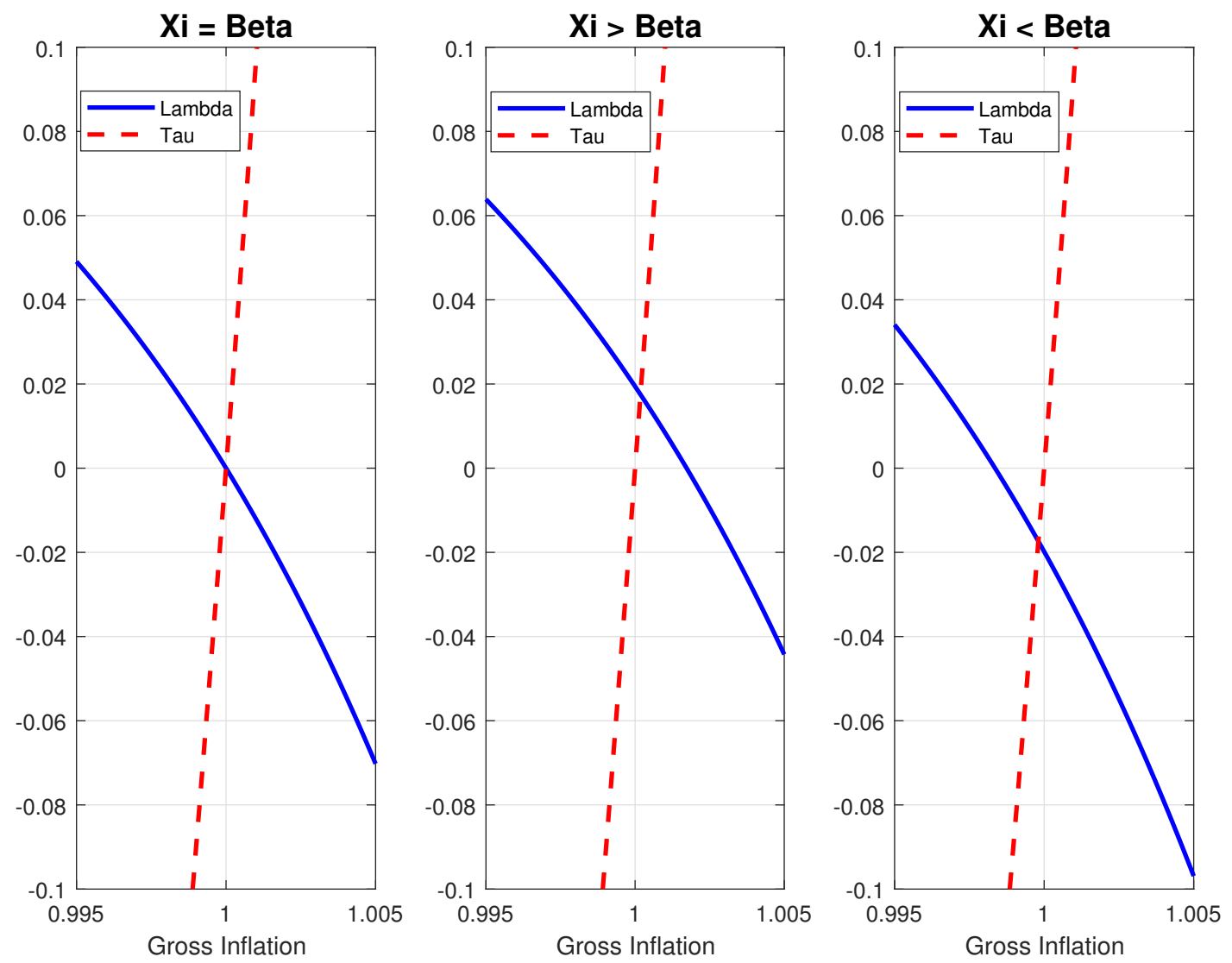

Figure 2: $\Lambda$ and $\Gamma$ according to the value of $\frac{\xi}{\beta}$ with Calvo pricing. In the first case, $\xi=\beta=0.99$. In the second case, $\xi=1$ and $\beta=0.99$. In the third case, $\xi=0.98$ and $\beta=0.99$. The other parameters are calibrated as follows: $\alpha=0.75, \theta=6, \varphi=0.5$. 


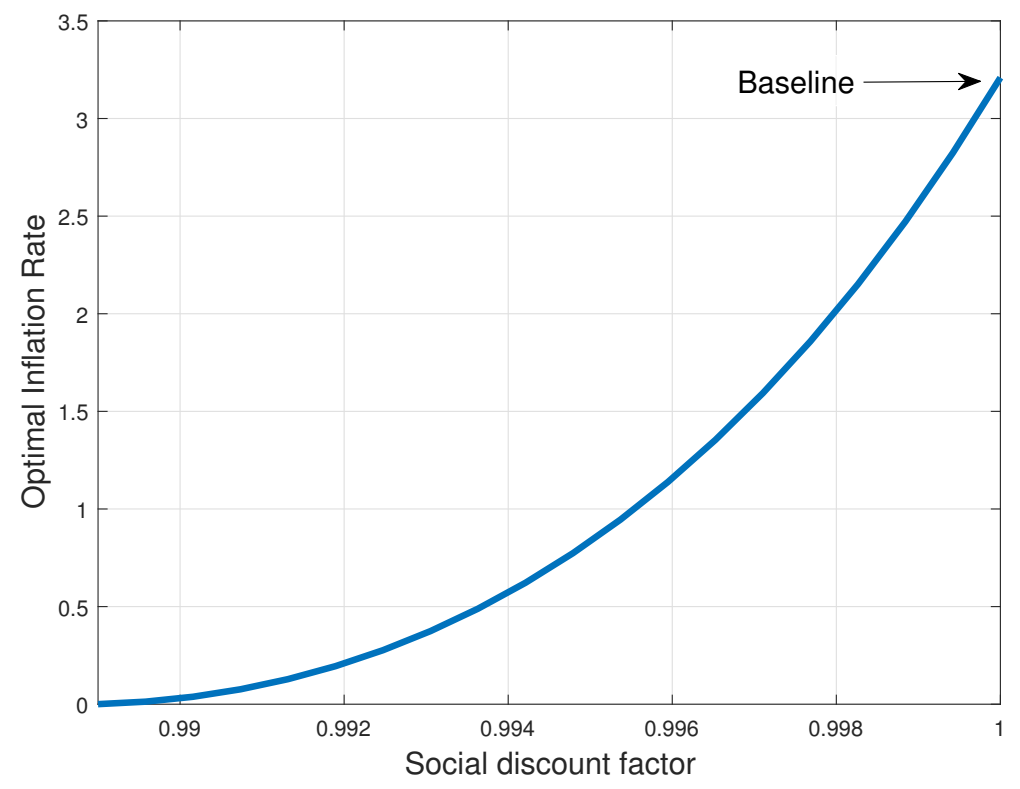

Figure 3: Optimal long-run inflation rate (in annual terms) according to the value of the social discount factor in a baseline calibrated version of the New Keynesian perpetual youth model.

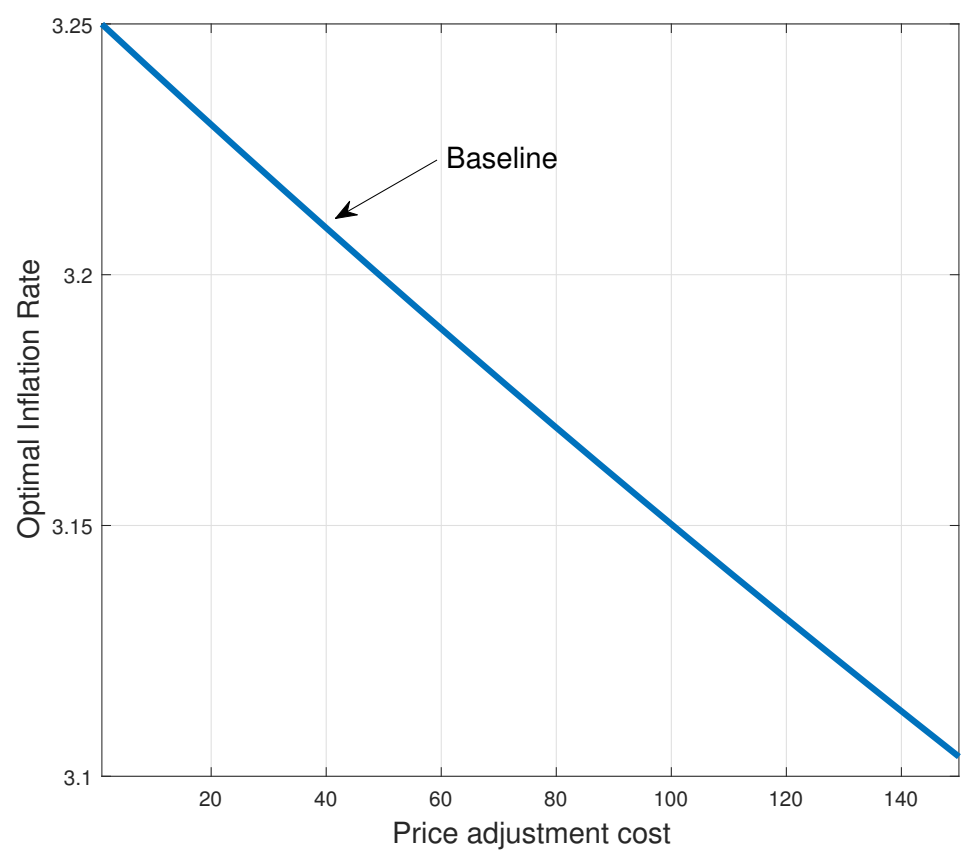

Figure 4: Optimal long-run inflation rate (in annual terms) according to the degree of price stickiness in a baseline calibrated version of the New Keynesian perpetual youth model. 


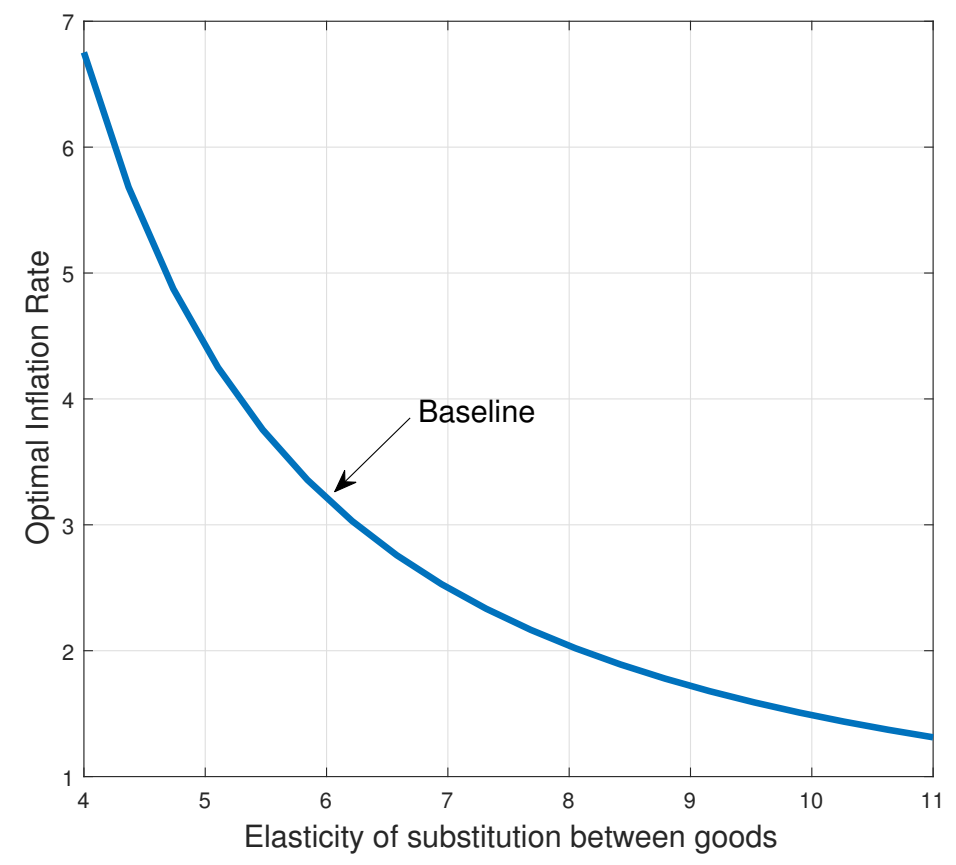

Figure 5: Optimal long-run inflation rate (in annual terms) according to the degree of monopolistic competition in a baseline calibrated version of the New Keynesian perpetual youth model.

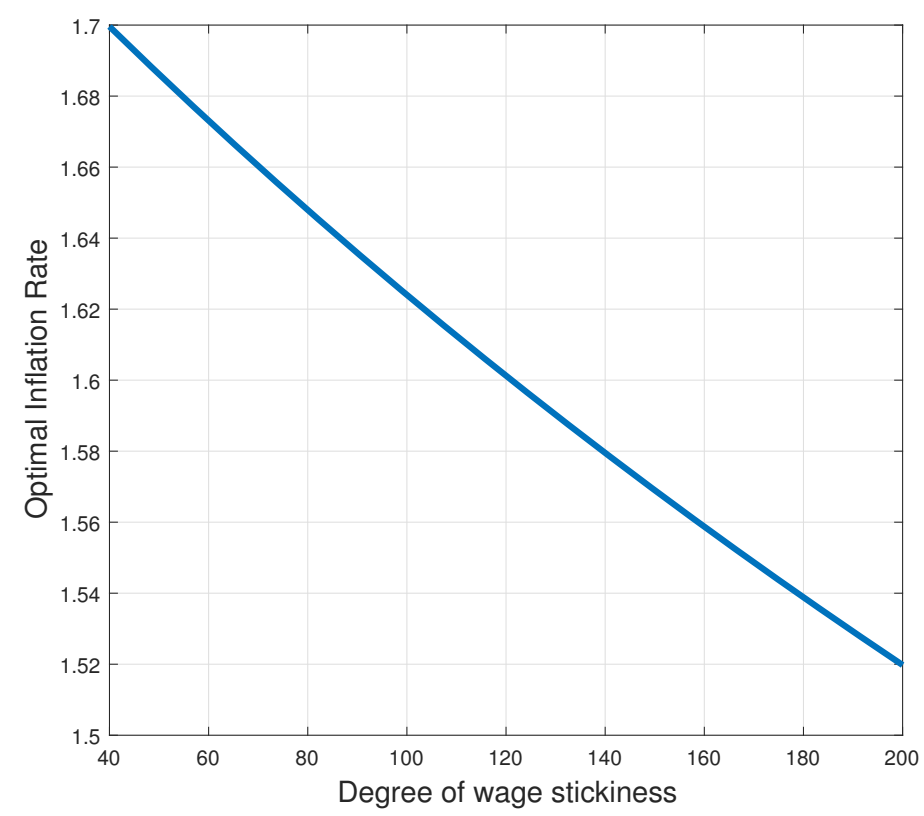

Figure 6: Optimal long-run inflation rate (in annual terms) according to the degree of wage stickiness in a baseline calibrated version of the New Keynesian model with search and matching frictions. 


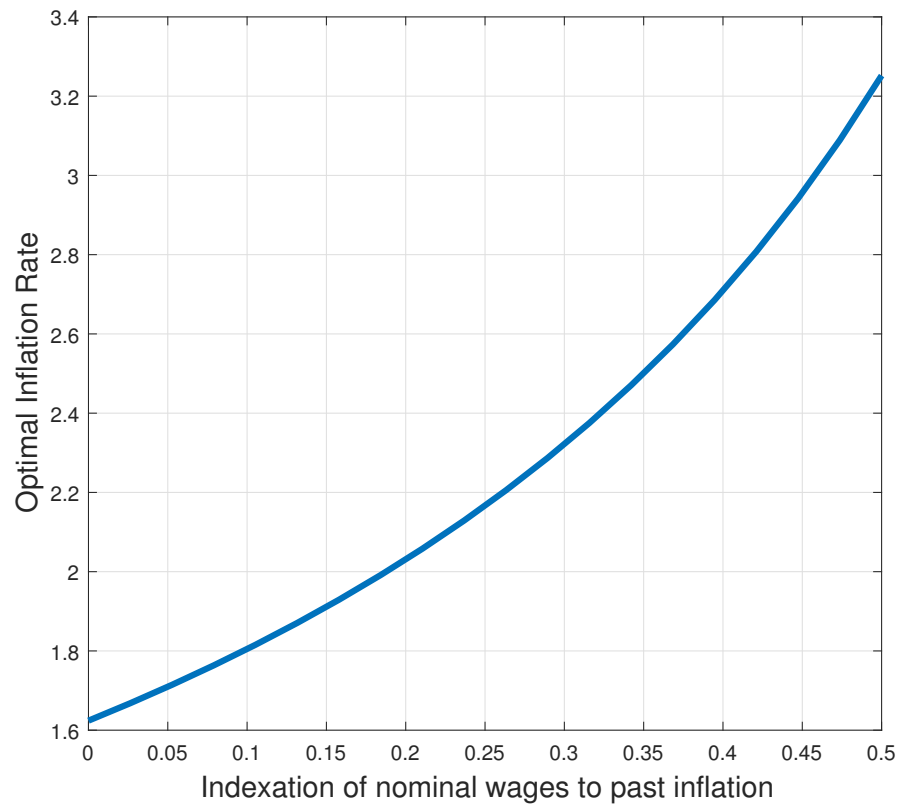

Figure 7: Optimal long-run inflation rate (in annual terms) according to the degree of indexation of nominal wages to past inflation in a baseline calibrated version of the New Keynesian model with search and matching frictions. 


\section{Appendix}

\subsection{Appendix 1: Optimal inflation formulas with Calvo pricing in the stan- dard New Keynesian model}

In the model of price setting based on Calvo (1983), each firms may reset its price only with probability $1-\alpha$ in any given period, independent of the time elapsed since the last adjustment. The optimal pricing condition of firms is

$$
p_{t}^{o}+\frac{\theta}{\theta-1} m c_{t}+E_{t} \sum_{s=t+1}^{\infty}(\alpha \beta)^{s-t}\left(\prod_{i=1}^{s-t} \Pi_{t+i}^{-1}\right)^{-\theta}\left\{p_{t}^{o}\left(\prod_{i=1}^{s-t} \Pi_{t+i}^{-1}\right)-\frac{\theta}{\theta-1} m c_{s}\right\}=0
$$

where $p_{t}^{o}=\frac{P_{t}^{o}}{P_{t}}$ is the relative price chosen by firms which can reset prices, and $P_{t}$ is the aggregate price in the economy at time $t$. The dynamics of inflation are described by the following equation

$$
1=(1-\alpha)\left(p_{t}^{o}\right)^{1-\theta}+\alpha \Pi_{t}^{\theta-1}
$$

Moreover, price dispersion leads to a dispersion in the quantity of varieties produced by firms. Since aggregate output is a concave function of the quantity of each variety, this dispersion leads to a costly decrease in output captured by

$$
s_{t}=(1-\alpha)\left(p_{t}^{o}\right)^{-\theta}+\alpha \Pi_{t}^{\theta} s_{t-1}
$$

In this environment, $s_{t}$ does not only depend on the time $t$ inflation rate but also on all past inflation rates $\Pi_{t-i} \forall i=\mathbb{N}^{+}$. Symmetrically, $m c_{t}$ depends on the time $t$ inflation rate and on all future expected inflation rates $E_{t} \Pi_{t+i} \forall i \in \mathbb{N}^{+}$. As in the case of Rotemberg pricing, we can rewrite (9) as a function of the effect of inflation on utility operating through marginal costs $\Lambda_{t}$ and the effect of inflation on utility operating through price dispersion $\Gamma_{t}$

$$
E_{0}\left\{\Lambda_{t}-\Gamma_{t}\right\}=0
$$

where

$$
\Lambda_{t}=\sum_{h=-t}^{0}\left[m c_{t+h}^{-1}-s_{t+h}\right]\left(\xi^{t+h} \frac{\partial m c_{t+h}}{\partial \Pi_{t}}\right)
$$




$$
\Gamma_{t}=\sum_{h=0}^{\infty}\left[\varphi s_{t+h}^{-1}+m c_{t+h}\right]\left(\xi^{t+h} \frac{\partial s_{t+h}}{\partial \Pi_{t}}\right)
$$

After using equations (43) to (45), under the assumptions that $\alpha \Pi^{\theta}<1^{5}$ and $t \rightarrow \infty$, we can find an analytical solution for the steady state expressions of $\Lambda$ and $\Gamma$ (see below)

$$
\begin{gathered}
\Lambda=\left[m c(\Pi)^{-1}-s(\Pi)\right] \frac{(\theta-1)}{\theta} p^{o}(\Pi) \frac{\alpha \Pi^{\theta-2}}{1-\alpha \beta \Pi^{\theta-1}} \frac{\left[\left(1-\frac{\beta}{\xi} \Pi\right)\left(1-\alpha \frac{\beta}{\xi} \Pi^{\theta-1}\right)+(\theta-1)\left(1-\Pi^{\prime} \frac{\beta}{\xi}\left(1-\alpha \Pi^{\theta-1}\right)\right]\right.}{\left(1-\alpha \Pi^{\theta-1}\right)\left(1-\alpha \frac{\beta}{\xi} \Pi^{\theta-1}\right)} \\
\Gamma=\left[\varphi s(\Pi)^{-1}+m c(\Pi)\right] \frac{\theta(1-\alpha)\left(p^{o}(\Pi)\right)^{-\theta} \alpha \Pi^{\theta-2}}{\left(1-\alpha \xi \Pi^{\theta}\right)\left(1-\alpha \Pi^{\theta}\right)\left(1-\alpha \Pi^{\theta-1}\right)}(\Pi-1)
\end{gathered}
$$

Figure 2 plots $\Lambda$ and $\Gamma$ for different values of the ratio $\xi / \beta$. Several things can be learned from this figure. First, the discounted effect of inflation on present and future price dispersion terms is equal to zero when $\Pi=1$. When $\Pi<1$, an increase in inflation reduces price dispersion today and in the future ( $\Gamma$ is negative). Symmetrically, when $\Pi>1$, a decrease in inflation reduces price dispersion today and in the future ( $\Gamma$ is positive). Second, the discounted effect of current inflation on past and present marginal costs $\Lambda$ is equal to zero when the social and private discount factors $\xi$ and $\beta$ are equal, and when steady-state inflation is equal to zero. The rationale for this result is similar to the one outlined above with Rotemberg pricing. The average markup is decreasing in current inflation, and increasing in future expected inflation. The effect operating through current inflation tends to dominate the one operating through anticipated inflation for low positive rates of inflation (Goodfriend and King 1997). The average markup is indeed minimized for such a rate. However, events happening before time $t$ loom larger for the Ramsey planner than events happening at time $t$. That is, the detrimental effects of current inflation on past markups are given a higher weight than its beneficial effects on current markups. When social and private discount rates coincide, these average markup and weighting effects offset each other for an inflation rate of zero.

\footnotetext{
${ }^{5}$ Even for a high value of price stickiness $\alpha=0.8$ and a high elasticity of substitution between goods $\theta=11$, this is valid as long as quarterly steady-state inflation is lower than $2.05 \%$. When $\alpha=0.9$ and $\theta=11$, quarterly steady-state inflation has to be lower than $0.96 \%$.
} 


\section{Derivation of $\Lambda$}

We start with the pricing condition

$$
E_{t} \sum_{s=t}^{\infty}(\alpha \beta)^{s-t} \frac{U_{c}\left(C_{s}\right)}{U_{c}\left(C_{t}\right)}\left(\frac{P_{t}}{P_{s}}\right)^{-\theta} Y_{s}\left\{p_{t}^{o} \frac{P_{t}}{P_{s}}-\frac{\theta}{\theta-1} m c_{s}\right\}=0
$$

Imposing market clearing $C_{s}=Y_{s}$, and assuming log utility in consumption, we obtain

$$
E_{t} \sum_{s=t}^{\infty}(\alpha \beta)^{s-t}\left(\frac{P_{t}}{P_{s}}\right)^{-\theta} p_{t}^{o} \frac{P_{t}}{P_{s}}=E_{t} \sum_{s=t}^{\infty}(\alpha \beta)^{s-t}\left(\frac{P_{t}}{P_{s}}\right)^{-\theta} \frac{\theta}{\theta-1} m c_{s}
$$

We can express marginal cost as a function of the current period optimal price $p_{t}^{o}$, future inflation rates $\Pi_{t+1}, \Pi_{t+2}, \ldots$, and future marginal costs $m c_{t+1}, m c_{t+2}, \ldots$

$$
\begin{gathered}
m c_{t}=\frac{\theta-1}{\theta} p_{t}^{o} E_{t}\left[1+\alpha \beta \Pi_{t+1}^{\theta-1}+(\alpha \beta)^{2}\left(\Pi_{t+1} \Pi_{t+2}\right)^{\theta-1}+\ldots\right] \\
-\alpha \beta E_{t} \Pi_{t+1}^{\theta} m c_{t+1}-(\alpha \beta)^{2} E_{t}\left(\Pi_{t+1} \Pi_{t+2}\right)^{\theta} m c_{t+2}+\ldots
\end{gathered}
$$

This equation is also valid one period ahead

$$
\begin{gathered}
m c_{t+1}=\frac{\theta-1}{\theta} p_{t+1}^{o} E_{t+1}\left[1+\alpha \beta \Pi_{t+2}^{\theta-1}+(\alpha \beta)^{2}\left(\Pi_{t+2} \Pi_{t+3}\right)^{\theta-1}+\ldots\right] \\
-\alpha \beta E_{t+1} \Pi_{t+2}^{\theta} m c_{t+2}-(\alpha \beta)^{2} E_{t+1}\left(\Pi_{t+2} \Pi_{t+3}\right)^{\theta} m c_{t+3}+\ldots
\end{gathered}
$$

We use this last equation to substitute out $m c_{t+1}$, and obtain

$$
\begin{gathered}
m c_{t}=\frac{\theta-1}{\theta} p_{t}^{o} E_{t}\left[1+\alpha \beta \Pi_{t+1}^{\theta-1}+(\alpha \beta)^{2}\left(\Pi_{t+1} \Pi_{t+2}\right)^{\theta-1}+\ldots\right] \\
-\alpha \beta E_{t} \Pi_{t+1}^{\theta} \frac{\theta-1}{\theta} p_{t+1}^{o}\left[1+\alpha \beta \Pi_{t+2}^{\theta-1}+(\alpha \beta)^{2}\left(\Pi_{t+2} \Pi_{t+3}\right)^{\theta-1}+\ldots\right]
\end{gathered}
$$


This last expression can be rewritten as

$$
m c_{t}=\frac{\theta-1}{\theta} p_{t}^{o}+\frac{\theta-1}{\theta} E_{t}\left(p_{t}^{o}-p_{t+1}^{o} \Pi_{t+1}\right)\left[\alpha \beta \Pi_{t+1}^{\theta-1}+(\alpha \beta)^{2}\left(\Pi_{t+1} \Pi_{t+2}\right)^{\theta-1}+\ldots\right]
$$

We now derive the effect of future expected inflation on marginal cost

- $\frac{\partial m c_{t}}{\partial \Pi_{t}}=\frac{\theta-1}{\theta} \frac{\partial p_{t}^{o}}{\partial \Pi_{t}}\left[1+\alpha \beta \Pi_{t+1}^{\theta-1}+(\alpha \beta)^{2}\left(\Pi_{t+1} \Pi_{t+2}\right)^{\theta-1}+\ldots\right]$

- $\frac{\partial m c_{t}}{\partial E_{t} \Pi_{t+1}}=\frac{(\theta-1)^{2}}{\theta} E_{t}\left(p_{t}^{o}-p_{t+1}^{o} \Pi_{t+1}\right) \Pi_{t+1}^{\theta-2}\left[\alpha \beta+(\alpha \beta)^{2}\left(\Pi_{t+2}\right)^{\theta-1}+\ldots\right]$

- $-\frac{\theta-1}{\theta}\left(\frac{\partial p_{t+1}^{o}}{\partial \Pi_{t+1}} \Pi_{t+1}+p_{t+1}^{o}\right)\left[\alpha \beta \Pi_{t+1}^{\theta-1}+(\alpha \beta)^{2}\left(\Pi_{t+1} \Pi_{t+2}\right)^{\theta-1}+\ldots\right]$

- $\frac{\partial m c_{t}}{\partial E_{t} \Pi_{t+2}}=\frac{(\theta-1)^{2}}{\theta} E_{t}\left(p_{t}^{o}-p_{t+1}^{o} \Pi_{t+1}\right) \Pi_{t+2}^{\theta-2}\left[(\alpha \beta)^{2} \Pi_{t+1}^{\theta-1}+(\alpha \beta)^{3}\left(\Pi_{t+1} \Pi_{t+3}\right)^{\theta-1}+\ldots\right]$

Under the assumption that $\alpha \beta \Pi^{\theta}$ is lower than 1 , we obtain in steady state

- $\frac{\partial m c}{\partial \Pi}=\frac{\theta-1}{\theta} \frac{\partial p^{o}}{\partial \Pi} \frac{1}{1-\alpha \beta \Pi^{\theta-1}}$

- $\frac{\partial m c}{\partial \Pi_{+1}}=\frac{(\theta-1)^{2}}{\theta} p^{o}(1-\Pi) \frac{\Pi^{-1} \alpha \beta \Pi^{\theta-1}}{1-\alpha \beta \Pi^{\theta-1}}-\frac{\theta-1}{\theta} \alpha \beta \Pi^{\theta-1}\left(\frac{\partial p^{o}}{\partial \Pi} \Pi+p^{o}\right) \frac{1}{1-\alpha \beta \Pi^{\theta-1}}$

- $\frac{\partial m c}{\partial \Pi_{+2}}=\frac{(\theta-1)^{2}}{\theta} p^{o}(1-\Pi) \frac{\Pi^{-1}\left(\alpha \beta \Pi^{\theta-1}\right)^{2}}{1-\alpha \beta \Pi^{\theta-1}}$

where, with a slight abuse of notation, we have written the derivative $\frac{\partial m c_{t}}{\partial E_{t} \Pi_{t+n}}$ evaluated in steady state as $\frac{\partial m c}{\partial \Pi_{+n}}$. For $n \geq 2$, all derivatives share a common form

- $\frac{\partial m c}{\partial \Pi_{+n}}=\frac{(\theta-1)^{2}}{\theta} p^{o}(1-\Pi) \frac{\Pi^{-1}\left(\alpha \beta \Pi^{\theta-1}\right)^{n}}{1-\alpha \beta \Pi^{\theta-1}}$

We can now compute what the planner cares about, the discounted effect of inflation on marginal cost

$$
\Xi=\frac{\Lambda}{m c(\Pi)^{-1}-s(\Pi)}=\sum_{i=0}^{\infty}\left(\xi^{-1}\right)^{i} \frac{\partial m c}{\partial \Pi_{+i}}
$$

After some algebra, we obtain

$$
\Xi=\frac{(\theta-1)}{\theta} p^{o} \frac{\alpha \Pi^{\theta-2}}{1-\alpha \beta \Pi^{\theta-1}} \frac{\left[\left(1-\frac{\beta}{\xi} \Pi\right)\left(1-\alpha \frac{\beta}{\xi} \Pi^{\theta-1}\right)+(\theta-1)(1-\Pi) \frac{\beta}{\xi}\left(1-\alpha \Pi^{\theta-1}\right)\right]}{\left(1-\alpha \Pi^{\theta-1}\right)\left(1-\alpha \frac{\beta}{\xi} \Pi^{\theta-1}\right)}
$$

where $p^{o}=\left[\frac{1-\alpha \Pi^{\theta-1}}{1-\alpha}\right]^{\frac{1}{1-\theta}}$. 


\section{Derivation of $\Gamma$}

We have

$$
s_{t}=(1-\alpha)\left(p_{t}^{o}\right)^{-\theta}+\alpha \Pi_{t}^{\theta} s_{t-1}
$$

Iterating backward, we obtain

$$
s_{t}=(1-\alpha)\left[\left(p_{t}^{o}\right)^{-\theta}+\alpha \Pi_{t}^{\theta}\left(p_{t-1}^{o}\right)^{-\theta}+\alpha^{2}\left(\Pi_{t} \Pi_{t-1}\right)^{\theta}\left(p_{t-2}^{o}\right)^{-\theta}+\ldots\right]
$$

We can derive the effect of current and past inflation on $s_{t}$

- $\frac{\partial s_{t}}{\partial \Pi_{t}}=-\theta(1-\alpha)\left(p_{t}^{o}\right)^{-\theta-1} \frac{\partial p_{t}^{o}}{\partial \Pi_{t}}+(1-\alpha) \theta \Pi_{t}^{\theta-1}\left[\alpha\left(p_{t-1}^{o}\right)^{-\theta}+\alpha^{2} \Pi_{t-1}^{\theta}\left(p_{t-2}^{o}\right)^{-\theta}+\ldots\right]$

- $\frac{\partial s_{t}}{\partial \Pi_{t-1}}=-\theta(1-\alpha) \alpha \Pi_{t}^{\theta}\left(p_{t-1}^{o}\right)^{-\theta-1} \frac{\partial p_{t-1}^{o}}{\partial \Pi_{t-1}}+(1-\alpha) \theta \Pi_{t-1}^{\theta-1}\left[\alpha^{2} \Pi_{t}^{\theta}\left(p_{t-2}^{o}\right)^{-\theta}+\alpha^{3}\left(\Pi_{t} \Pi_{t-2}\right)^{\theta}\left(p_{t-3}^{o}\right)^{-\theta}+\ldots\right]$

- $\frac{\partial s_{t}}{\partial \Pi_{t-2}}=-\theta(1-\alpha) \alpha^{2}\left(\Pi_{t} \Pi_{t-1}\right)^{\theta}\left(p_{t-2}^{o}\right)^{-\theta-1} \frac{\partial p_{t-2}^{o}}{\partial \Pi_{t-2}}+(1-\alpha) \theta \Pi_{t-2}^{\theta-1}\left[\alpha^{3}\left(\Pi_{t} \Pi_{t-1}\right)^{\theta}\left(p_{t-3}^{o}\right)^{-\theta}+\ldots\right]$

Under the assumption that $\alpha \Pi^{\theta}$ is lower than 1 , we obtain in steady state

- $\frac{\partial s}{\partial \Pi}=\theta(1-\alpha)\left(p^{o}\right)^{-\theta} \frac{\alpha \Pi^{\theta-2}}{\left(1-\alpha \Pi^{\theta-1}\right)\left(1-\alpha \Pi^{\theta}\right)}(\Pi-1)$

- $\frac{\partial s}{\partial \Pi_{-1}}=\alpha \Pi^{\theta} \frac{\partial s}{\partial \Pi}$

- $\frac{\partial s}{\partial \Pi_{-2}}=\left(\alpha \Pi^{\theta}\right)^{2} \frac{\partial s}{\partial \Pi}$

where, again, $\frac{\partial s}{\partial \Pi_{-n}}$ is the derivative $\frac{\partial s}{\partial \Pi_{t-n}}$ evaluated in steady state. For $n \geq 2$, all derivatives share a common form

- $\frac{\partial s}{\partial \Pi_{-n}}=\left(\alpha \Pi^{\theta}\right)^{n} \frac{\partial s}{\partial \Pi}$

We can now compute what the planner cares about, the discounted effect of inflation on price dispersion

$$
\Phi=\frac{\Gamma}{\varphi s(\Pi)^{-1}+m c(\Pi)}=\sum_{i=0}^{\infty} \xi^{i} \frac{\partial s}{\partial \Pi_{-i}}
$$

After some algebra, we find

$$
\Phi=\frac{\theta(1-\alpha)\left(p^{o}\right)^{-\theta} \alpha \Pi^{\theta-2}}{\left(1-\alpha \xi \Pi^{\theta}\right)\left(1-\alpha \Pi^{\theta}\right)\left(1-\alpha \Pi^{\theta-1}\right)}(\Pi-1)
$$




\subsection{Appendix 2: Ramsey problem in the New Keynesian model with a perpetual youth structure}

\subsubsection{Setting up the problem}

Since I am only interested in solving for the steady state of the Ramsey problem, I abstract from uncertainty. I also drop all expectation operators in order to lighten the notation. The relevant constraints faced by the Ramsey planner are the Phillips curve, the definition of dividends, the Euler equations for shares and bonds (one per cohort), the intratemporal conditions for the optimal choice of consumption and hours worked (one per cohort), the individual budget constraints of households (one per cohort) as well as the bridge equations for aggregate consumption, aggregate hours worked and aggregate shares.

$$
\begin{gathered}
1-\theta+\theta w_{t}-\phi^{p} \Pi_{t}\left(\Pi_{t}-1\right)+\frac{\Pi_{t+1}}{1+R_{t}} \phi^{p} \Pi_{t+1}\left(\Pi_{t+1}-1\right) \frac{Z_{t+1} L_{t+1}}{Z_{t} L_{t}}=0 \\
D_{t}=L_{t}\left(1-\frac{\phi^{p}}{2}\left(\Pi_{t}-1\right)^{2}\right)-w_{t} L_{t} \\
Q_{t}=\beta \frac{C_{j, t}}{C_{j, t+1}}\left(Q_{t+1}+D_{t+1}\right) \\
\beta \frac{C_{j, t}}{C_{j, t+1}} \frac{1+R_{t}}{\Pi_{t+1}}=1 \\
C_{j, t}+Q_{t} S_{j, t}=\frac{C_{j, t}}{1-L_{j, t}}=w_{t} \\
L_{t}=\sum_{j=-\infty}^{t} \gamma(1-\gamma)^{t-j} L_{j, t} \\
C_{t}=\sum_{j=-\infty}^{t} \gamma(1-\gamma)^{t-j} C_{j, t}
\end{gathered}
$$




$$
1=\sum_{j=-\infty}^{t} \gamma(1-\gamma)^{t-j} S_{j, t}
$$

This set of constraints can be simplified in a few steps:

- Introduce the definition of the stochastic discount factor $\beta \frac{C_{j, t}}{C_{j, t+1}}=\beta_{t, t+1}$.

- Use the bridge equations for consumption and shares to aggregate the cohort-specific budget constraints and substitute out the equation for dividends. We obtain an aggregate resource constraint.

- Operate a change of variables $S_{j, t-1}=\frac{\Omega_{j, t}(1-\gamma)}{Q_{t}+D_{t}}$ and substitute out share prices $Q_{t}$ in the cohort-specific budget constraints.

- Use the intratemporal household optimality condition and the bridge equation for hours worked to substitute out $L_{j, t}$ and $L_{t}$.

- Assume that the planner chooses directly the allocation and drop the individual Euler equations. It can be shown to be equivalent to choosing a path $\left\{R_{t}\right\}_{t=0}^{\infty}$.

At this stage, provided that $\frac{\beta(1-\gamma)}{\xi}<1$, the aggregate welfare function (38) is equal to

$$
W_{0}=\sum_{t=0}^{\infty} \xi^{t}\left[\frac{\gamma}{1-\frac{\beta(1-\gamma)}{\xi}}\left(\chi \log (\chi)-\chi \log \left(w_{t}\right)\right)+(1+\chi) \sum_{j=-\infty}^{t} \gamma\left(\frac{\beta(1-\gamma)}{\xi}\right)^{t-j} \log \left(C_{j, t}\right)\right]
$$

and the constraints are given by

$$
\begin{gathered}
1-\theta+\theta w_{t}-\phi^{p} \Pi_{t}\left(\Pi_{t}-1\right)+\beta_{t, t+1} \phi^{p} \Pi_{t+1}\left(\Pi_{t+1}-1\right) \frac{1-\frac{\chi}{w_{t+1}} C_{t+1}}{1-\frac{\chi}{w_{t}} C_{t}}=0 \\
\beta \frac{C_{j, t}}{C_{j, t+1}}=\beta_{t, t+1} \\
C_{j, t}(1+\chi)+\beta_{t, t+1}(1-\gamma) \Omega_{j, t+1}=\Omega_{j, t}+w_{t} \\
C_{t}=L_{t}\left(1-\frac{\phi^{p}}{2}\left(\Pi_{t}-1\right)^{2}\right)
\end{gathered}
$$




$$
C_{t}=\sum_{j=-\infty}^{t} \gamma(1-\gamma)^{t-j} C_{j, t}
$$

where, again, there is one budget constraint and one equation linking consumption growth to the stochastic discount factor for each cohort. We now go one step further and get rid of cohort-specific variables. First, as shown in the main text, we can express the consumption level of newly-born households as a function of aggregate variables only. For generation $j$

$$
C_{j, j} \frac{1+\chi}{1-\beta(1-\gamma)}=w_{j}+\sum_{h=1}^{\infty} \beta_{j, j+h}(1-\gamma)^{h} w_{j+h}
$$

Second, we can express the consumption level of generation $j$ at any given time $t$ as a function of $C_{j, j}$ and a series of stochastic discount factors

$$
C_{j, t}=\frac{\beta^{t-j}}{\beta_{j, t}} C_{j, j}
$$

where $\beta_{j, t}=\beta_{j, j+1} \beta_{j+1, j+2} \ldots \beta_{t-1, t}$. This permits to express all $C_{j, t}$ for $j=-\infty, \ldots, t$ as a function of aggregate variables only. In the end, the central bank chooses aggregate consumption, inflation, wages, and stochastic discount factors to maximize the following Lagrangian

$$
\begin{gathered}
L=\sum_{t=0}^{\infty} \xi^{t}\left(-\frac{\chi \gamma}{1-\frac{\beta(1-\gamma)}{\xi}} \log \left(w_{t}\right)+(1+\chi) \sum_{j=-\infty}^{t} \gamma\left(\frac{\beta(1-\gamma)}{\xi}\right)^{t-j}\left[\log \left(w_{j}+\sum_{h=1}^{\infty} \beta_{j, j+h}(1-\gamma)^{h} w_{j+h}\right)-\log \left(\beta_{j, t}\right)\right]\right. \\
+\lambda_{1 t}\left[\frac{\theta-1}{\theta}+\frac{\phi^{p}}{\theta} \Pi_{t}\left(\Pi_{t}-1\right)-\beta_{t, t+1} \frac{\phi^{p}}{\theta} \Pi_{t+1}\left(\Pi_{t+1}-1\right) \frac{1-\frac{\chi}{w_{t+1}} C_{t+1}}{1-\frac{\chi}{w_{t}} C_{t}}-w_{t}\right] \\
+\lambda_{2 t}\left[\left(1-\frac{\phi^{p}}{2}\left(\Pi_{t}-1\right)^{2}\right)\left(1-\frac{\chi}{w_{t}} C_{t}\right)-C_{t}\right] \\
\left.+\lambda_{3 t}\left[\sum_{j=-\infty}^{t} \gamma(1-\gamma)^{t-j} \frac{\beta^{t-j}}{\beta_{j, t}}\left(w_{j}+\sum_{h=1}^{\infty} \beta_{j, j+h}(1-\gamma)^{h} w_{j+h}\right)-\frac{1+\chi}{1-\beta(1-\gamma)} C_{t}\right]\right)
\end{gathered}
$$

I compute first-order conditions in time $t=t_{1}$, where $t_{1}$ is arbitrarily large. Due to the dynamic nature of consumption and pricing decisions, such choices for time $t_{1}$ consumption, inflation, wages, and stochastic discount factors will have an effet on real outcomes in other periods as well. 


\subsubsection{Solving the Ramsey problem}

The infinite sums that are present in the welfare function and the third constraint make it very difficult to compute optimal monetary policy in response to shocks. They do, however, make it possible to derive analytical expressions for the first-order conditions in steady state by applying standard formulas for infinite geometric series. Provided that some restrictions on $\beta, \xi, \gamma$ and $\tilde{\beta}$ are verified, the first-order conditions evaluated in steady state are

- FOC n $^{\circ} 1: \lambda_{3} \frac{\gamma(1-\gamma) w}{1-\beta(1-\gamma)^{2}}\left[\frac{1}{1-\tilde{\beta}(1-\gamma)} \frac{1}{1-\frac{\hat{\beta}}{\xi}(1-\gamma)}-\frac{\beta \xi}{\tilde{\beta}^{2}} \frac{1}{1-\frac{\beta \xi(1-\gamma)}{\tilde{\beta}}} \frac{1}{1-\frac{\beta}{\tilde{\beta}}(1-\gamma)}\right]$

- $-\frac{\beta(1-\gamma)}{\tilde{\beta}} \frac{\gamma}{1-\frac{\beta}{\xi}(1-\gamma)} \frac{1+\chi}{1-\beta(1-\gamma)}+\frac{\gamma(1-\gamma)(1+\chi)}{1-\frac{\beta}{\xi} \tilde{\beta}(1-\gamma)^{2}}\left[\frac{1}{1-\beta(1-\gamma)}+\frac{\frac{\tilde{\beta}}{\xi}(1-\gamma)}{1-\frac{\tilde{\beta}}{\xi}(1-\gamma)}\right]-\lambda_{1} \frac{\phi^{p}}{\theta} \Pi(\Pi-1)=0$

- FOC $n^{\circ} 2: \lambda_{1} \frac{\phi^{p}}{\theta}(2 \Pi-1)\left(1-\frac{\tilde{\beta}}{\xi}\right)-\lambda_{2} \phi^{p}(\Pi-1) L=0$

- $\operatorname{FOC~n}{ }^{\circ} 3:-\lambda_{1} \frac{\chi}{w L} \tilde{\beta} \frac{\phi^{p}}{\theta} \Pi(\Pi-1)\left(1-\frac{1}{\xi}\right)-\lambda_{2}\left(1+\left(1-\frac{\phi^{p}}{2}(\Pi-1)^{2}\right) \frac{\chi}{w}\right)-\frac{1+\chi}{1-\beta(1-\gamma)} \lambda_{3}=0$

- FOC n ${ }^{\circ} 4: \frac{\gamma(1+\chi)}{w} \frac{1-\tilde{\beta}(1-\gamma)}{1-\frac{\beta}{\xi} \tilde{\beta}(1-\gamma)^{2}}\left[\frac{1}{1-\beta(1-\gamma)}+\frac{\frac{\tilde{\beta}}{\xi}(1-\gamma)}{1-\frac{\hat{\beta}}{\xi}(1-\gamma)}\right]-\frac{\chi \gamma}{1-\frac{\beta(1-\gamma)}{\xi}} \frac{1}{w}+\lambda_{3} \frac{\gamma}{1-\beta(1-\gamma)^{2}}\left[\frac{1}{1-\frac{\beta \xi(1-\gamma)}{\hat{\beta}}}+\frac{\frac{\tilde{\beta}}{\xi}(1-\gamma)}{1-\frac{\tilde{\beta}(1-\gamma)}{\xi}}\right]$

- $-\lambda_{1}\left[1+\tilde{\beta} \frac{\phi^{p}}{\theta} \Pi(\Pi-1) \frac{1-L}{w L}\left(\frac{1}{\xi}-1\right)\right]+\lambda_{2}\left(1-\frac{\phi^{p}}{2}(\Pi-1)^{2}\right) \frac{1-L}{w}=0$

where FOC $n^{\circ} 1$ is the first-order condition with respect to $\beta_{t, t+1}$, FOC n ${ }^{\circ} 2$ is the first-order condition with respect to $\Pi_{t}, \mathrm{FOC} \mathrm{n}^{\circ} 3$ is the first-order condition with respect to $C_{t}$, and FOC $\mathrm{n}^{\circ} 4$ is the first-order condition with respect to $w_{t}$. The constraints to the Ramsey problem can be used to solve for $\tilde{\beta}, w$ and $L$ as a function of $\Pi$. Given this, we can use FOCs $n^{\circ} 1, n^{\circ} 3$ and $n^{\circ} 4$ to solve for $\lambda_{1}, \lambda_{2}, \lambda_{3}$ as a function of $\Pi$. FOC $n^{\circ} 2$ then determines the optimal inflation rate. I rewrite the system as

- $F O C n^{\circ} 1: \lambda_{3} \omega_{1}-\omega_{2}-\lambda_{1} \frac{\phi^{p}}{\theta} \Pi(\Pi-1)=0$

- $\operatorname{FOC~n}{ }^{\circ} 2: \lambda_{1} \frac{1}{\theta}(2 \Pi-1)\left(1-\frac{\tilde{\beta}}{\xi}\right)-\lambda_{2}(\Pi-1) L=0$

- $\mathrm{FOC} \mathrm{n}{ }^{\circ} 3:-\lambda_{1} \omega_{3}-\lambda_{2} \omega_{4}-\frac{1+\chi}{1-\beta(1-\gamma)} \lambda_{3}=0$

- $\mathrm{FOC} n^{\circ} 4: \omega_{5}+\lambda_{3} \omega_{6}-\lambda_{1} \omega_{7}+\lambda_{2} \omega_{8}=0$

where

$$
\begin{aligned}
& \text { - } \omega_{1}=\frac{\gamma(1-\gamma) w}{1-\beta(1-\gamma)^{2}}\left[\frac{1}{1-\tilde{\beta}(1-\gamma)} \frac{1}{1-\frac{\tilde{\beta}}{\xi}(1-\gamma)}-\frac{\beta \xi}{\tilde{\beta}^{2}} \frac{1}{1-\frac{\beta \xi(1-\gamma)}{\tilde{\beta}}} \frac{1}{1-\frac{\beta}{\beta}(1-\gamma)}\right] \\
& \text { - } \omega_{2}=\frac{\beta(1-\gamma)}{\tilde{\beta}} \frac{\gamma}{1-\frac{\beta}{\xi}(1-\gamma)} \frac{1+\chi}{1-\beta(1-\gamma)}-\frac{\gamma(1-\gamma)(1+\chi)}{1-\frac{\beta}{\xi} \tilde{\beta}(1-\gamma)^{2}}\left[\frac{1}{1-\beta(1-\gamma)}+\frac{\frac{\tilde{\beta}}{\xi}(1-\gamma)}{1-\frac{\hat{\beta}}{\xi}(1-\gamma)}\right]
\end{aligned}
$$


- $\omega_{3}=\frac{\chi}{w L} \tilde{\beta} \frac{\phi^{p}}{\theta} \Pi(\Pi-1)\left(1-\frac{1}{\xi}\right)$

- $\omega_{4}=1+\left(1-\frac{\phi^{p}}{2}(\Pi-1)^{2}\right) \frac{\chi}{w}$

- $\omega_{5}=\frac{\gamma(1+\chi)}{w} \frac{1-\tilde{\beta}(1-\gamma)}{1-\frac{\beta}{\xi} \tilde{\beta}(1-\gamma)^{2}}\left[\frac{1}{1-\beta(1-\gamma)}+\frac{\frac{\tilde{\beta}}{\xi}(1-\gamma)}{1-\frac{\tilde{\beta}}{\xi}(1-\gamma)}\right]-\frac{\chi \gamma}{1-\frac{\beta(1-\gamma)}{\xi}} \frac{1}{w}$

- $\omega_{6}=\frac{\gamma}{1-\beta(1-\gamma)^{2}}\left[\frac{1}{1-\frac{\beta \xi(1-\gamma)}{\tilde{\beta}}}+\frac{\frac{\tilde{\beta}}{\xi}(1-\gamma)}{1-\frac{\tilde{\beta}(1-\gamma)}{\xi}}\right]$

- $\omega_{7}=1+\tilde{\beta} \frac{\phi^{p}}{\theta} \Pi(\Pi-1) \frac{1-L}{w L}\left(\frac{1}{\xi}-1\right)$

- $\omega_{8}=\left(1-\frac{\phi^{p}}{2}(\Pi-1)^{2}\right) \frac{1-L}{w}$

Using FOCs $n^{\circ} 1, n^{\circ} 3$, and $n^{\circ} 4$, I obtain the following expressions for $\lambda_{1}$ and $\lambda_{2}$

$$
\begin{gathered}
\lambda_{1}=\frac{-\omega_{5}-\frac{\omega_{2}}{\omega_{1}} \omega_{6}+\frac{1+\chi}{1-\beta(1-\gamma)} \frac{\omega_{2} \omega_{8}}{\omega_{1} \omega_{4}}}{-\omega_{7}-\frac{\omega_{3} \omega_{8}}{\omega_{4}}+\frac{\frac{\phi^{p}}{\theta} \Pi(\Pi-1)}{\omega_{1}}\left(\omega_{6}-\frac{\omega_{8}}{\omega_{4}} \frac{1+\chi}{1-\beta(1-\gamma)}\right)} \\
\lambda_{2}=-\frac{1+\chi}{1-\beta(1-\gamma)} \frac{\omega_{2}}{\omega_{1} \omega_{4}}-\lambda_{1}\left(\frac{\frac{\phi^{p}}{\theta} \Pi(\Pi-1)}{\omega_{1} \omega_{4}} \frac{1+\chi}{1-\beta(1-\gamma)}+\frac{\omega_{3}}{\omega_{4}}\right)
\end{gathered}
$$

In a zero-inflation steady state, $\Pi=1$ and $\mathrm{FOC} \mathrm{n}^{\circ} 2$ implies that

$$
-\frac{-\omega_{5} \omega_{1}+\omega_{2}\left(\frac{1+\chi}{1-\beta(1-\gamma)} \frac{1-L}{w+\chi}-\omega_{6}\right)}{\theta}\left(1-\frac{\tilde{\beta}}{\xi}\right)=0
$$

This equality is verified in two cases:

- When $\theta$ tends towards infinity, $\tilde{\beta}$ tends towards $\beta$ and this condition is verified regardless of the value of $\xi$. In that case, although the steady state is inefficient ( $\xi$ differs from $\tilde{\beta}$ ), zero inflation is optimal as monetary policy loses its leverage over markups.

- When $\theta$ is finite, this condition is verified if the social discount factor $\xi$ tracks exactly the value of the stochastic discount factor $\tilde{\beta}$ prevailing in the zero-inflation steady state.

This proves the proposition in the main text. 


\subsection{Appendix 3: Optimal long-run inflation in Bilbiie, Fujiwara and Ghi- roni $(2014)$}

This section derives the Ramsey problem in Bilbiie, Fujiwara and Ghironi (2014) for an arbitrary value of the social discount factor $\xi$. I use the notations of the aforementioned paper. The monetary authority chooses $L_{t}, \pi_{t}, L_{C, t}$ and $N_{t+1}$ to maximize

$$
\begin{gathered}
\operatorname{Max}_{L_{t}, \pi_{t}, L_{C, t}, N_{t+1}} E_{0} \sum_{t=0}^{\infty} \xi^{t}\left(\ln \left[\left(1-\frac{\kappa}{2} \pi_{t}^{2}\right) Z_{t} \rho\left(N_{t}\right) L_{C, t}\right]-h\left(L_{t}\right)\right. \\
+\eta_{1, t}\left[N_{t+1}-(1-\delta)\left(N_{t}+\frac{\left(L_{t}-L_{C, t}\right) Z_{t}}{f_{E}}\right)\right] \\
+\eta_{2, t}\left[\left(1-\theta\left(N_{t}\right)\right)\left(1-\frac{\kappa}{2} \pi_{t}^{2}\right)+\theta\left(N_{t}\right)\left(1-\frac{\kappa}{2} \pi_{t}^{2}\right) L_{C, t} h_{L}\left(L_{t}\right)-\kappa \pi_{t}\left(1+\pi_{t}\right)+\beta(1-\delta) \kappa \pi_{t+1}\left(1+\pi_{t+1}\right) \frac{N_{t}}{N_{t+1}} \frac{1-\frac{\kappa}{2} \pi_{t}^{2}}{1-\frac{\kappa}{2} \pi_{t+1}^{2}}\right] \\
\left.+\eta_{3, t}\left[h_{L}\left(L_{t}\right) \frac{f_{E}}{Z_{t}}-\beta(1-\delta)\left(h_{L}\left(L_{t+1}\right) \frac{f_{E}}{Z_{t+1}}+\frac{1-L_{C, t+1} h_{L}\left(L_{t+1}\right)}{N_{t+1}}\right)\right]\right)
\end{gathered}
$$

where $\xi$ is the social discount factor. The first-order conditions evaluated in steady state are equal to

- $L_{t}:-1-\frac{\eta_{1}}{h_{L}(L)}(1-\delta)+\eta_{2} \theta(N)\left(1-\frac{\kappa}{2} \pi^{2}\right) \frac{L_{C}}{L} \varphi+\eta_{3} \frac{\varphi}{L}\left[1-\frac{\beta(1-\delta)}{\xi}+\frac{\beta(1-\delta)}{\xi} \frac{L_{C}}{N}\right]=0$

- $\pi_{t}: \frac{-\pi}{1-\frac{\kappa}{2} \pi^{2}}-\eta_{2}\left(\pi\left(1-\theta\left(N_{t}\right)+\theta\left(N_{t}\right) L_{C, t} h_{L}\left(L_{t}\right)\right)+\beta(1-\delta) \kappa \pi^{2}(1+\pi) \frac{1}{1-\frac{\kappa}{2} \pi^{2}}+1+2 \pi_{t}-\frac{\beta(1-\delta)}{\xi} \frac{1+\frac{\kappa}{2} \pi^{2}+2 \pi}{1-\frac{\kappa}{2} \pi^{2}}\right)=$ 0

- $L_{C, t}: 1+\eta_{1} L_{C}(1-\delta)+\eta_{2} \theta(N)\left(1-\frac{\kappa}{2} \pi^{2}\right) L_{C} h_{L}(L)+\eta_{3} \frac{\beta(1-\delta)}{\xi} \frac{L_{C} h_{L}(L)}{N}=0$

- $N_{t+1}: \xi \epsilon(N)+\eta_{1} N(1-\xi(1-\delta))-\eta_{2} \beta(1-\delta) \kappa \pi(1+\pi)(1-\xi)+\xi \eta_{2} N \theta_{N}(N)\left(1-\frac{\kappa}{2} \pi^{2}\right)\left(L_{C} h_{L}(L)-1\right)+$ $\eta_{3} \beta(1-\delta) \frac{1-L_{C} h_{L}(L)}{N}=0$

Consider the FOCs above in a zero-inflation steady state $(\pi=0)$

- FOC ${ }^{\circ} 1:-1-\frac{\eta_{1}}{h_{L}(L)}(1-\delta)+\eta_{2} \theta(N) \frac{L_{C}}{L} \varphi+\eta_{3} \frac{\varphi}{L}\left[1-\frac{\beta(1-\delta)}{\xi}+\frac{\beta(1-\delta)}{\xi} \frac{L_{C}}{N}\right]=0$

- $F O C n^{\circ} 2:-\eta_{2}\left(1-\frac{\beta(1-\delta)}{\xi}\right)=0$

- FOC n $3: 1+\eta_{1} L_{C}(1-\delta)+\eta_{2}(\theta(N)-1)+\eta_{3} \frac{\beta(1-\delta)}{\xi} \frac{\theta(N)-1}{\theta(N)} \frac{1}{N}=0$ 
- FOC n ${ }^{\circ} 4: \xi \epsilon(N)+\eta_{1} N(1-\xi(1-\delta))-\eta_{2} \xi \eta_{2} N \frac{\theta_{N}(N)}{\theta(N)}+\eta_{3} \frac{\beta(1-\delta)}{\theta(N) N}=0$

We can solve for $\eta_{1}, \eta_{2}$ and $\eta_{3}$ using FOCs $n^{\circ} 1, \mathrm{n}^{\circ} 3$ and $\mathrm{n}^{\circ} 4$ and substitute the resulting expression of $\eta_{2}$ in FOC $\mathrm{n}^{\circ} 2$. By doing so, we get an equality that has to be verified for zero inflation to be optimal. Substituting out $\eta_{3}$ using FOC n4

- FOC $n^{\circ} 1:-1-\frac{\xi}{\beta(1-\delta)} \epsilon(N) \theta(N) \frac{\varphi}{L} N\left(1-\frac{\beta(1-\delta)}{\xi}+\frac{\beta(1-\delta)}{\xi} \frac{L_{C}}{N}\right)$

- $-\eta_{1}\left[\frac{1-\delta}{h_{L}(L)}+\left(\frac{1-\xi(1-\delta)}{\beta(1-\delta)}\right) \theta(N) N^{2} \frac{\varphi}{L}\left(1-\frac{\beta(1-\delta)}{\xi}+\frac{\beta(1-\delta)}{\xi} \frac{L_{C}}{N}\right)\right]$

- $+\eta_{2} \frac{\varphi}{L}\left[\theta(N) L_{C}+\frac{\xi}{\beta(1-\delta)} \theta_{N}(N) N^{2}\left(1-\frac{\beta(1-\delta)}{\xi}+\frac{\beta(1-\delta)}{\xi} \frac{L_{C}}{N}\right)\right]=0$

- $\mathrm{FOC} n^{\circ} 3: L_{C, t}: 1-\epsilon(N)(\theta(N)-1)+\eta_{1}\left(L_{C}(1-\delta)-(1-\xi(1-\delta)) \frac{(\theta(N)-1) N}{\xi}\right)+\eta_{2}(\theta(N)-1)\left(1+\frac{\theta_{N}(N) N}{\theta(N)}\right)=$ 0

Relabeling

- $\mathrm{FOC} \mathrm{n}{ }^{\circ} 1: \omega_{1}-\eta_{1} \omega_{2}+\eta_{2} \omega_{3}=0$

- $\operatorname{FOC~n} 3: 1-\epsilon(N)(\theta(N)-1)+\eta_{1} \omega_{4}+\eta_{2}(\theta(N)-1)\left(1+\frac{\theta_{N}(N) N}{\theta(N)}\right)=0$

And solving for $\eta_{2}$

$$
\eta_{2}=\frac{-\omega_{2}(1-\epsilon(N)(\theta(N)-1))-\omega_{4} \omega_{1}}{\omega_{3} \omega_{4}+\omega_{2}(\theta(N)-1)\left(1+\frac{\theta_{N}(N) N}{\theta(N)}\right)}
$$

Substituting the expression of $\eta_{2}$ in $\mathrm{FOC} \mathrm{n}^{\circ} 2$, we get an equality that has to be verified for optimal inflation to be zero

$$
\frac{\omega_{2}(1-\epsilon(N)(\theta(N)-1))+\omega_{4} \omega_{1}}{\omega_{3} \omega_{4}+\omega_{2}(\theta(N)-1)\left(1+\frac{\theta_{N}(N) N}{\theta(N)}\right)}\left(1-\frac{\beta(1-\delta)}{\xi}\right)=0
$$

where

- $\omega_{1}=-1-\xi \epsilon(N) \frac{\varphi}{L} \frac{\theta(N) N}{\beta(1-\delta)}\left[1-\frac{\beta(1-\delta)}{\xi}+\frac{\beta(1-\delta)}{\xi} \frac{L_{C}}{N}\right]$

- $\omega_{2}=\frac{1-\delta}{h_{L}(L)}+(1-\xi(1-\delta)) \frac{\varphi}{L} \frac{\theta(N) N^{2}}{\beta(1-\delta)}\left(1-\frac{\beta(1-\delta)}{\xi}+\frac{\beta(1-\delta)}{\xi} \frac{L_{C}}{N}\right)$

- $\omega_{3}=\frac{\varphi}{L}\left[\theta(N) L_{C}+\frac{\xi}{\beta(1-\delta)} \theta_{N}(N) N^{2}\left(1-\frac{\beta(1-\delta)}{\xi}+\frac{\beta(1-\delta)}{\xi} \frac{L_{C}}{N}\right)\right]$

- $\omega_{4}=L_{C}(1-\delta)-(1-\xi(1-\delta)) \frac{(\theta(N)-1) N}{\xi}$

The equality is verified in two distinct cases. 
Case 1: Efficient steady state $\left(\epsilon(N)=\frac{1}{\theta(N)-1}\right)$ and $\xi=\beta$.

Equation (46) becomes

$$
\frac{\omega_{4} \omega_{1}}{\omega_{3} \omega_{4}+\omega_{2}(\theta(N)-1)\left(1+\frac{\theta_{N}(N) N}{\theta(N)}\right)} \delta=0
$$

Noting that in steady state $\frac{\delta}{1-\delta} N+L_{C}=L, \omega_{1}$ simplifies to

$$
\omega_{1}=-1-\varphi \frac{\theta(N)}{\theta(N)-1}<0
$$

$\omega_{1}$ is negative as long as $\theta(N)>1$. Moreover, we know that in steady state $h_{L}(L)(1-\beta(1-\delta))-$ $\beta(1-\delta) \frac{1-L_{C} h_{L}(L)}{N}=0$. This implies

$$
(\theta(N)-1) \frac{N}{\beta}(1-\beta(1-\delta))-(1-\delta) L_{C}=0
$$

and thus $\omega_{4}=0$. Given that $\omega_{2}>0, \theta(N)>1$ and $\theta_{N}(N)>0$ for all preference specifications considered in the paper, we conclude that (46) is verified in that particular case. Zero long-run inflation is optimal.

Case 2: Inefficient steady state and $\xi=\beta(1-\rho)$.

The second term in $(46), 1-\frac{\beta(1-\delta)}{\xi}$, is equal to zero. Thus, as long as the denominator of the first term is different from zero, the equality is verified and optimal inflation is equal to zero in the long run.

\subsection{Appendix 4: Optimal long-run inflation in a model with search and matching frictions and costly wage bargaining}

I consider a New Keynesian model with search and matching frictions in the labor market and nominal wage stickiness. It is similar to the one developed in Lepetit (2018) except wages are bargained over and firms incur a cost of adjusting nominal wages.

\subsubsection{Labor market}

The size of the labor force is normalized to unity. Workers and firms need to match in order to become productive. The number of matches in period $t$ is given by a Cobb-Douglas matching function 
$m_{t}=\chi s_{t}^{\alpha} v_{t}^{1-\alpha}, s_{t}$ being the number of job seekers and $v_{t}$ the number of vacancies posted by firms. The parameter $\chi$ reflects the efficiency of the matching process and $\alpha \in[0,1]$ is the elasticity of the matching function with respect to unemployment. Define $\theta_{t}=\frac{v_{t}}{s_{t}}$ as labor market tightness. The probability $q_{t}$ for a firm to fill a vacancy and the probability $p_{t}$ for a worker to find a job are, respectively, $q_{t}=\frac{m_{t}}{v_{t}}=\chi \theta_{t}^{-\alpha}$ and $p_{t}=\frac{m_{t}}{s_{t}}=\chi \theta_{t}^{1-\alpha}$. At the beginning of each period $t$, a fraction $\rho$ of existing employment relationships $N_{t-1}$ is exogenously destroyed. Those $\rho N_{t-1}$ newly separated workers and the $1-N_{t-1}$ workers unemployed in the previous period form the pool of job seekers $s_{t}=1-(1-\rho) N_{t-1}$. Job seekers have a probability $p_{t}$ of finding a job within the period. The law of motion of employment $N_{t}$ is accordingly given by

$$
N_{t}=(1-\rho) N_{t-1}+p_{t}\left(1-(1-\rho) N_{t-1}\right)
$$

The number of unemployed workers in period $t$ is $u_{t}=1-N_{t}$.

\subsubsection{Households}

Household members receive a nominal wage $W_{t}$ when employed and a real value $b$ of home production when unemployed. I assume that consumption risks are fully pooled within the household. Household members have expected intertemporal utility

$$
E_{0} \sum_{t=0}^{\infty} \beta^{t} \frac{C_{t}^{1-\sigma}}{1-\sigma}
$$

where $\beta$ is the household's subjective discount factor, $\sigma$ the coefficient of relative risk aversion, and $C_{t}$ the consumption level of each household member. Households receive profits $\Pi_{t}^{r}$ from retail firms and invest in risk-free bonds $B_{t+1}$ that promise a unit of currency tomorrow and cost $\left(1+R_{t}\right)^{-1}$ today. They face the following per period budget constraint

$$
P_{t} C_{t}+\left(1+R_{t}\right)^{-1} B_{t+1}=P_{t}\left[\frac{W_{t}}{P_{t}} N_{t}+b\left(1-N_{t}\right)\right]+B_{t}+P_{t} \Pi_{t}^{r}
$$

Consumption of market goods is given by $C_{t}^{m}=C_{t}-b\left(1-N_{t}\right) . \quad C_{t}^{m} \equiv\left[\int_{0}^{1} C_{t}^{m}(j)^{\frac{\varepsilon-1}{\varepsilon}} d j\right]^{\frac{\varepsilon}{\varepsilon-1}}$ is a Dixit-Stiglitz aggregator of the different varieties of goods produced by the retail sector and $\varepsilon$ is the elasticity of substitution between the different varieties. The optimal allocation of income on each variety is given by $C_{t}^{m}(j)=\left[\frac{P_{t}(j)}{P_{t}}\right]^{-\varepsilon} C_{t}^{m}$, where $P_{t}=\left[\int_{0}^{1} P_{t}(j)^{\frac{\varepsilon-1}{\varepsilon}} d j\right]^{\varepsilon /(1-\varepsilon)}$ is the price index and 
$P_{t}(j)$ is the price of a good of variety $j$. Households choose bonds holding so as to maximize (48) subject to (49). The household's optimal consumption path is governed by a standard Euler equation

$$
\beta E_{t} \frac{1+I_{t}}{\Pi_{t+1}}\left(\frac{C_{t+1}}{C_{t}}\right)^{-\sigma}=1
$$

where $\Pi_{t+1}=\frac{P_{t+1}}{P_{t}}$ is the gross inflation rate between periods $t$ and $t+1$.

\subsubsection{Wholesale firms}

A measure one of wholesale firms, indexed by $i$, produce according to the following technology

$$
Y_{i t}^{w}=Z_{t} N_{i t}
$$

where $Z_{t}$ is a common, aggregate productivity disturbance. Wholesale firms sell their output in a competitive market at a price $P_{t}^{w}$. Posting a vacancy comes at a cost $\kappa$ and firms must incur a cost $c_{i t}^{w}=\frac{\phi^{w}}{2}\left(\frac{W_{i t}}{W_{i t-1} \Pi_{t-1}^{t}}-1\right)^{2}$ per worker when adjusting nominal wages. These costs are indexed to lagged inflation with coefficient $\iota$. Firm $i$ chooses its level of employment $N_{i t}$ and the number of vacancies $v_{i t}$ in order to maximize the expected sum of its discounted profits

$$
E_{0} \sum_{t=0}^{\infty} \beta^{t} \frac{C_{t}^{-\sigma}}{C_{0}^{-\sigma}}\left[\frac{P_{t}^{w}}{P_{t}} Y_{i t}^{w}-\kappa v_{i t}-\frac{W_{i t}}{P_{t}} N_{i t}-c_{i t}^{w} N_{i t}\right]
$$

subject to its perceived law of evolution of employment $N_{i t}=(1-\rho) N_{i t-1}+v_{i t} q\left(\theta_{t}\right)$, and taking wages as given. I assume symmetry across workers and firms, and therefore, drop individual subscripts $i$. After rearranging the first-order conditions, the following job creation equation obtains

$$
\frac{\kappa}{q\left(\theta_{t}\right)}=\frac{Z_{t}}{\mu_{t}}-\frac{W_{t}}{P_{t}}-c_{t}^{w}+E_{t} \beta_{t, t+1}(1-\rho) \frac{\kappa}{q\left(\theta_{t+1}\right)}
$$

where $\beta_{t, t+1}=\beta\left(\frac{C_{t+1}}{C_{t}}\right)^{-\sigma}$ is the stochastic discount factor of households between periods $t$ and $t+1$ and $\mu_{t}=\frac{P_{t}}{P_{t}^{w}}$ is the markup of retail over wholesale prices.

\subsubsection{Wage bargaining}

The value of a filled vacancy for a firm is 


$$
J_{t}=\frac{Z_{t}}{\mu_{t}}-\frac{W_{t}}{P_{t}}-c_{t}^{w}+E_{t} \beta_{t, t+1}(1-\rho) J_{t+1}
$$

and free entry implies that $\frac{\kappa}{q\left(\theta_{t}\right)}=J_{t}$. The value of being employed for a worker is

$$
H_{t}=\frac{W_{t}}{P_{t}}+E_{t} \beta_{t, t+1}\left[(1-\rho) H_{t+1}+\rho p_{t+1} H_{t+1}+\rho\left(1-p_{t+1}\right) U_{t+1}\right]
$$

and the value of being unemployed is

$$
U_{t}=b+E_{t} \beta_{t, t+1}\left[p_{t+1} H_{t+1}+\left(1-p_{t+1}\right) U_{t+1}\right]
$$

Firms and workers bargain over nominal wages in order to maximize

$$
\operatorname{argmax}_{\left\{W_{t}\right\}}\left[\left(J_{t}\right)^{\eta}\left(H_{t}-U_{t}\right)^{1-\eta}\right]
$$

where $1-\eta$ is the bargaining power of workers. We obtain the following sharing rule

$$
J_{t}=\eta_{t}\left(H_{t}-U_{t}+J_{t}\right)
$$

where $\eta_{t}=\frac{\eta \gamma_{t}}{1-\eta+\eta \gamma_{t}}$ is a modified bargaining power, after taking into account the effect of adjustment costs, and

$$
\gamma_{t}=1+\frac{\phi^{w}}{w_{t}} \frac{\Pi_{t}^{w}}{\Pi_{t-1}^{\iota}}\left(\frac{\Pi_{t}^{w}}{\Pi_{t-1}^{\iota}}-1\right)-E_{t} \beta_{t, t+1}(1-\rho) \frac{\phi^{w}}{w_{t}} \frac{\Pi_{t+1}^{w}}{\Pi_{t}^{\iota}}\left(\frac{\Pi_{t+1}^{w}}{\Pi_{t}^{\iota}}-1\right)
$$

where $\Pi_{t}^{w}=\frac{W_{t}}{W_{t-1}}$. In the absence of productivity growth, $\Pi^{w}=\Pi$ in steady state and $\gamma$ grows with $\Pi$ as long as $\iota<1$. Given that $\frac{\partial \eta_{t}}{\partial \gamma_{t}}=\frac{\eta(1-\eta)}{\left(1-\eta+\eta \gamma_{t}\right)^{2}}>0$, this implies that the share of the match surplus accruing to firms rises with inflation. The rationale for this result is as follows. As in the other models considered in this paper, the effects of wage and price inflation are dynamic. Higher wage inflation at time $t$ is associated with larger adjustment costs and a lower firm surplus at time $t$, but with lower adjustment costs and a higher firm surplus at time $t+1$. Because the future is discounted with a factor $\beta(1-\rho)$, these effects are asymmetric. Therefore, an increase in the time $t$ wage inflation rate raises average adjustment costs. These costs are partially shared with workers through the bargaining process. Without adjustment costs, an increasing in nominal wages leads to symmetric variations in firms' and worker's surpluses. As a result, maximizing a weighted average of these surpluses implies 
sharing the overall surplus according to the exogenous weight $\eta$. With adjustment costs, increasing nominal wages decreases firms' surplus by more than it increases workers' surplus. In that case, maximizing the objective function is consistent with putting a larger weight on firm outcomes, with the weight depending on the size of adjustment costs. In steady state, wage inflation is equal to price inflation, adjustment costs rise with inflation, and so does the bargaining power of firms.

After some algebra, we obtain the following wage equation

$$
w_{t}=\frac{W_{t}}{P_{t}}=\left(1-\eta_{t}\right)\left(\frac{Z_{t}}{\mu_{t}}-c_{t}^{w}\right)+\eta_{t} b+E_{t} \beta_{t+1}(1-\rho) \frac{\kappa}{q\left(\theta_{t+1}\right)}\left(1-\eta_{t}-\left(1-p_{t+1}\right)\left(1-\eta_{t+1}\right) \frac{\eta_{t}}{\eta_{t+1}}\right)
$$

\subsubsection{Retail firms}

There is a large number of retailers, indexed by $j$, who buy the goods produced by wholesale firms at a price $P_{t}^{w}$ and transform them one for one into differentiated goods. The real marginal cost of production for retailers is given by $m c_{t}=\frac{P_{t}^{w}}{P_{t}}$. They face quadratic costs of adjusting prices

$\Theta_{t}(j)=\frac{\phi^{p}}{2}\left(\frac{P_{t}(j)}{P_{t-1}(j)}-1\right)^{2} Y_{t}$, which are measured in terms of aggregate output $Y_{t}$. Retail firms choose $P_{t}(j)$ in order to maximize

$$
E_{0} \sum_{t=0}^{\infty} \beta^{t} \frac{C_{t}^{-\sigma}}{C_{0}^{-\sigma}}\left[\frac{P_{t}(j)-P_{t}^{w}}{P_{t}} Y_{t}(j)-\Theta_{t}(j)\right]
$$

subject to the demand for each variety $Y_{t}(j)=\left(P_{t}(j) / P_{t}\right)^{-\epsilon} Y_{t}^{d}$ where $Y_{t}^{d}$ is aggregate demand for final goods. Noting that in the symmetric equilibrium $P_{t}(j)=P_{t}$, we obtain

$$
1-\varepsilon+\frac{\varepsilon}{\mu_{t}}-\phi^{p} \Pi_{t}\left(\Pi_{t}-1\right)+E_{t} \beta_{t+1} \phi^{p} \Pi_{t+1}\left(\Pi_{t+1}-1\right) \frac{Z_{t+1} N_{t+1}}{Z_{t} N_{t}}=0
$$

\subsubsection{Equilibrium}

The economy-wide resource constraint is obtained by aggregating the budget constraints of households. Final output and home production can be used for consumption or to cover the deadweight costs of posting vacancies or changing prices and wages

$$
C_{t}=Z_{t} N_{t}\left(1-\frac{\phi^{p}}{2}\left(\Pi_{t}-1\right)^{2}\right)+b\left(1-N_{t}\right)-\kappa v_{t}-N_{t} c_{t}^{w}
$$


We can now define an equilibrium.

DEFInition: A competitive equilibrium is a set of plans $\left\{C_{t}, R_{t}, N_{t}, \mu_{t}, \theta_{t}, \Pi_{t}, w_{t}, \Pi_{t}^{w}, \eta_{t}, \gamma_{t}, c_{t}^{w}\right\}$ satisfying equations (47), (50), (53), (54), (55), (56), (57), the definitions $\Pi_{t}^{w}=\frac{w_{t}}{w_{t-1}} \Pi_{t}, \eta_{t}=\frac{\eta \gamma_{t}}{1-\eta+\eta \gamma_{t}}$,

$c_{t}^{w}=\frac{\phi^{w}}{2}\left(\frac{\Pi_{t}^{w}}{\Pi_{t-1}^{t}}-1\right)^{2}$, given a specification for the exogenous process $Z_{t}$ and for monetary policy $R_{t}$, and initial conditions $N_{-1}, \Pi_{-1}$.

\subsubsection{Ramsey optimal monetary policy}

I operate a change of variable by expressing markups as a function of marginal cost $\mu_{t}=\frac{1}{m c_{t}}$. The monetary authority chooses a sequence $\left\{\Pi_{t}, C_{t}, \theta_{t}, w_{t}, N_{t}, \Pi_{t}^{w}, c_{t}^{w}, \eta_{t}, \gamma_{t}, m c_{t}\right\}$ to maximize the following Lagrangian

$$
\begin{aligned}
& L=E_{0} \sum_{t=0}^{\infty} \xi^{t}\left(\frac{C_{t}^{1-\sigma}}{1-\sigma}+\lambda_{1 t}\left[Z_{t} m c_{t}-w_{t}-c_{t}^{w}+E_{t} \beta\left(\frac{C_{t+1}}{C_{t}}\right)^{-\sigma}(1-\rho) \frac{\kappa}{\chi} \theta_{t+1}^{\alpha}-\frac{\kappa}{\chi} \theta_{t}^{\alpha}\right]\right. \\
& +\lambda_{2 t}\left[(1-\rho) N_{t-1}+\chi \theta_{t}^{1-\alpha}\left(1-(1-\rho) N_{t-1}\right)-N_{t}\right] \\
& +\lambda_{3 t}\left[Z_{t} N_{t}\left(1-\frac{\phi^{p}}{2}\left(\Pi_{t}-1\right)^{2}\right)+b\left(1-N_{t}\right)-\kappa \theta_{t}\left(1-(1-\rho) N_{t-1}\right)-N_{t} c_{t}^{w}-C_{t}\right] \\
& +\lambda_{4 t}\left[\left(1-\eta_{t}\right)\left(Z_{t} m c_{t}-c_{t}^{w}\right)+\eta_{t} b+E_{t} \beta\left(\frac{C_{t+1}}{C_{t}}\right)^{-\sigma}(1-\rho) \frac{\kappa}{\chi} \theta_{t+1}^{\alpha}\left(1-\eta_{t}-\left(1-\chi \theta_{t+1}^{1-\alpha}\right)\left(1-\eta_{t+1}\right) \frac{\eta_{t}}{\eta_{t+1}}\right)-w_{t}\right] \\
& +\lambda_{5 t}\left[\frac{w_{t}}{w_{t-1}} \Pi_{t}-\Pi_{t}^{w}\right]+\lambda_{6 t}\left[\frac{\phi^{w}}{2}\left(\frac{\Pi_{t}^{w}}{\Pi_{t-1}^{\iota}}-1\right)^{2}-c_{t}^{w}\right]+\lambda_{7 t}\left[\frac{\eta \gamma_{t}}{1-\eta+\eta \gamma_{t}}-\eta_{t}\right] \\
& +\lambda_{8 t}\left[1+\frac{\phi^{w}}{w_{t}} \frac{\Pi_{t}^{w}}{\Pi_{t-1}^{\iota}}\left(\frac{\Pi_{t}^{w}}{\Pi_{t-1}^{\iota}}-1\right)-E_{t} \beta\left(\frac{C_{t+1}}{C_{t}}\right)^{-\sigma}(1-\rho) \frac{\phi^{w}}{w_{t}} \frac{\Pi_{t+1}^{w}}{\Pi_{t}^{L}}\left(\frac{\Pi_{t+1}^{w}}{\Pi_{t}^{L}}-1\right)-\gamma_{t}\right] \\
& \left.+\lambda_{9 t}\left[1-\varepsilon+\varepsilon m c_{t}-\phi^{p} \Pi_{t}\left(\Pi_{t}-1\right)+E_{t} \beta\left(\frac{C_{t+1}}{C_{t}}\right)^{-\sigma} \phi^{p} \Pi_{t+1}\left(\Pi_{t+1}-1\right) \frac{Z_{t+1} N_{t+1}}{Z_{t} N_{t}}\right]\right)
\end{aligned}
$$


The first-order conditions evaluated in steady state are

- $\Pi_{t}:-\lambda_{3} N \phi^{p}(\Pi-1)+\lambda_{5}-\iota \frac{\phi^{w}}{w} \Pi^{-\iota}\left(1-2 \Pi^{1-\iota}\right)(\beta(1-\rho)-\xi) \lambda_{8}-\phi^{p}(2 \Pi-1) \lambda_{9}\left(1-\frac{\beta}{\xi}\right)-$ $\xi \lambda_{6} \phi^{w} \iota \Pi^{-\iota}\left(\Pi^{1-\iota}-1\right)=0$

- $\theta_{t}:-\frac{\kappa}{\chi} \alpha \theta^{\alpha-1} \lambda_{1}\left(1-\frac{\beta}{\xi}(1-\rho)\right)+\lambda_{2} \chi(1-\alpha) \theta^{-\alpha}(1-(1-\rho) N)-\lambda_{3} \kappa(1-(1-\rho) N)+\lambda_{4} \frac{\beta}{\xi}(1-$ $\rho) \kappa(1-\tilde{\eta})=0$

- $w_{t}:-\lambda_{1}-\lambda_{4}+\lambda_{5} \frac{\Pi}{w}(1-\xi)-\lambda_{8} \frac{\phi^{w}}{w^{2}} \Pi^{1-\iota}\left(\Pi^{1-\iota}-1\right)(1-\beta(1-\rho))=0$

- $N_{t}:-\lambda_{2}\left(1-\xi(1-\rho)\left(1-\chi \theta^{1-\alpha}\right)\right)+\lambda_{3}\left(1-\frac{\phi^{p}}{2}(\Pi-1)^{2}-b-c^{w}+\xi \kappa \theta(1-\rho)\right)-\lambda_{9} \beta \phi^{p} \Pi(\Pi-1) \frac{1}{N}\left(1-\frac{1}{\xi}\right)=$ 0

- $\Pi_{t}^{w}:-\lambda_{5}+\lambda_{6} \phi^{w} \Pi^{-\iota}\left(\Pi^{1-\iota}-1\right)+\phi^{w} \Pi^{-\iota}\left(2 \Pi^{1-\iota}-1\right) \frac{\lambda_{8}}{w}\left(1-\frac{\beta}{\xi}(1-\rho)\right)$

- $c_{t}^{w}:-\lambda_{1}-\lambda_{3} N-\lambda_{4}(1-\tilde{\eta})-\lambda_{6}=0$

- $\eta_{t}: \lambda_{4}\left[b-m c+c^{w}+\beta(1-\rho) \frac{\kappa}{\tilde{\eta}}\left(\theta(1-\tilde{\eta})-\frac{\theta^{\alpha}}{\chi}+\frac{1}{\xi}\left(\frac{\theta_{t}^{\alpha}}{\chi}-\theta_{t}\right)\right)\right]-\lambda_{7}=0$

- $\gamma_{t}: \lambda_{7} \frac{\eta(1-\eta)}{(1-\eta+\eta \gamma)^{2}}-\lambda_{8}=0$

- $m c_{t}: \lambda_{1}+\lambda_{4}(1-\tilde{\eta})+\varepsilon \lambda_{9}=0$

- $C_{t}: C^{-\sigma}-\lambda_{3}+\sigma \beta C^{-1}(1-\rho)\left(1-\frac{1}{\xi}\right)\left[\lambda_{1} \frac{\kappa}{\chi} \theta^{\alpha}+\lambda_{4} \kappa \theta(1-\tilde{\eta})-\lambda_{8} \frac{\phi^{w}}{w} \Pi^{1-\iota}\left(\Pi^{1-\iota}-1\right)+\lambda_{9} \frac{\phi^{p}}{1-\rho} \Pi(\Pi-1)\right]=$ 0

where $\tilde{\eta}$ denotes the steady-state value of $\eta_{t}$. I now evaluate the system when $\Pi=1$, solve for the Lagrange multipliers, and substitute their expressions back in the first-order condition with respect to $\Pi_{t}$. I obtain the following condition

$$
-\omega_{3} C^{-\sigma} \frac{\left[\omega_{5} \omega_{1}+\left(\omega_{5} \omega_{4}-1\right) \frac{\phi^{p}}{\varepsilon}\left(1-\frac{\beta}{\xi}\right)+(1-\eta) \frac{\phi^{p}}{\varepsilon}\left(1-\frac{\beta}{\xi}\right)\right]}{\frac{\beta}{\xi}(1-\rho) \kappa(1-\eta)+\left(\omega_{5} \omega_{4}-1\right) \omega_{2}+\omega_{3}\left(\left(\omega_{5} \omega_{4}-1\right) \omega_{6}+\omega_{7}\right)}=0
$$

with

- $\omega_{1}=\eta(1-\eta) \frac{\phi^{w}}{w}\left(1-\frac{\beta}{\xi}(1-\rho)+\iota(\beta(1-\rho)-\xi)\right)$

- $\omega_{2}=-\frac{\kappa}{\chi} \alpha \theta^{\alpha-1}\left(1-\frac{\beta}{\xi}(1-\rho)\right)$

- $\omega_{3}=(1-(1-\rho) N)\left[\frac{(1-b+\xi \kappa \theta(1-\rho)) \chi(1-\alpha) \theta^{-\alpha}}{1-\xi(1-\rho)\left(1-\chi \theta^{1-\alpha}\right)}-\kappa\right]$

- $\omega_{4}=\eta(1-\eta) \frac{\phi^{w}}{w^{2}}\left(1-\frac{\beta}{\xi}(1-\rho)\right)(1-\xi)$ 
- $\omega_{5}=b-m c+\beta(1-\rho) \frac{\kappa}{\eta}\left(\theta(1-\eta)-\frac{\theta^{\alpha}}{\chi}+\frac{1}{\xi}\left(\frac{\theta_{t}^{\alpha}}{\chi}-\theta\right)\right)$

- $\omega_{6}=\sigma \beta C^{-1}(1-\rho)\left(1-\frac{1}{\xi}\right) \frac{\kappa}{\chi} \theta^{\alpha}$

- $\omega_{7}=\sigma \beta C^{-1}(1-\rho)\left(1-\frac{1}{\xi}\right) \kappa \theta(1-\eta)$

Zero inflation is optimal when this equality is verified. I consider different cases in order to understand the role played by each friction in isolation.

Case 1: Nominal wages are flexible, $\phi^{w}=0$ and prices are sticky $\phi^{p} \neq 0$.

In that case, $\omega_{1}$ and $\omega_{4}$ are equal to zero. The condition becomes

$$
-\omega_{3} C^{-\sigma} \frac{-\eta \frac{\phi^{p}}{\varepsilon}\left(1-\frac{\beta}{\xi}\right)}{\frac{\beta}{\xi}(1-\rho) \kappa(1-\eta)-\omega_{2}+\omega_{3}\left(-\omega_{6}+\omega_{7}\right)}=0
$$

As long as the denominator is different from zero, this equality is verified if $\beta=\xi$, or if the steady state is efficient, in which case $\omega_{3}=0$. In that case, inflation only influences real activity through price markups. Zero inflation is optimal if the social discount factor $\xi$ is equal to the steady state discount factor appearing in the price Phillips curve $\beta$.

Case 2: Nominal wages are sticky, $\phi^{w} \neq 0$ and prices are flexible $\phi^{p}=0$.

The condition becomes

$$
-\omega_{3} C^{-\sigma} \frac{\omega_{5} \omega_{1}}{\frac{\beta}{\xi}(1-\rho) \kappa(1-\eta)+\left(\omega_{5} \omega_{4}-1\right) \omega_{2}+\omega_{3}\left(\left(\omega_{5} \omega_{4}-1\right) \omega_{6}+\omega_{7}\right)}=0
$$

As long as the denominator is different from zero, this equality is verified if $\xi=\beta(1-\rho)$, in which case $\omega_{1}=0$, or if the steady state is efficient, in which case $\omega_{3}=0$. In that case, inflation only influences real activity through wage markups. Zero inflation is optimal is the social discount factor $\xi$ is equal to the steady state discount factor used by firms and workers during wage negotiations $\beta(1-\rho)$.

Case 3: Both nominal wages and prices are sticky, $\phi^{w} \neq 0$ and $\phi^{p} \neq 0$. 
The condition becomes

$$
-\omega_{3} C^{-\sigma} \frac{\left[\omega_{5} \omega_{1}+\left(\omega_{5} \omega_{4}-1\right) \frac{\phi^{p}}{\varepsilon}\left(1-\frac{\beta}{\xi}\right)+(1-\eta) \frac{\phi^{p}}{\varepsilon}\left(1-\frac{\beta}{\xi}\right)\right]}{\frac{\beta}{\xi}(1-\rho) \kappa(1-\eta)+\left(\omega_{5} \omega_{4}-1\right) \omega_{2}+\omega_{3}\left(\left(\omega_{5} \omega_{4}-1\right) \omega_{6}+\omega_{7}\right)}=0
$$

As long as the denominator is different from zero, this condition is verified only if the steady state is efficient, in which case $\omega_{3}=0$. Inflation influences real activity through both price and wage markups. When $\xi=\beta$, the discounted effects of inflation on price markups is equal to zero, but the discounted effects of inflation on wage markup is positive. As a result, optimal inflation is positive. When $\xi=\beta(1-\rho)$, the discounted effects of inflation on wage markups is zero, but the discounted effects of inflation on price markups is negative. As a result, optimal inflation is negative. Optimal inflation is equal to zero only when the steady state is efficient.

\section{Quantitative results}

I now solve for numerical values of the optimal long-run inflation rate by using the nine constraints to the Ramsey problem as well as the ten first-order conditions derived above. The model is parameterized as follows. A few parameters are calibrated similarly as in the model of section 2 in the main text. I set the household discount factor to $\beta=0.995$, the elasticity of substitution between goods to $\varepsilon=6$, the coefficient of relative risk aversion to $\sigma=1$ and the price adjustment cost parameter to $\phi^{p}=40$. In most estimated models, wage stickiness is found to be larger than price stickiness (see for example Furlanetto and Groshenny 2016 in a similar search and matching model). I thus choose $\phi^{w}=100$ and experiment with other values below. I also assume that the costs of adjusting nominal wages are not indexed to past inflation in the baseline and show some robustness exercises below. Turning to labor market parameters, I fix the elasticity of matches with respect to unemployment at $\alpha=0.5$, within the range of plausible values proposed by Petrongolo and Pissarides (2001). I set the values of unemployment and labor market tightness in a zero-inflation steady state to $5 \%$ and 0.7 respectively, and the quarterly job separation probability to 0.1. These targets imply through the steady-state employment flow equation a quarterly job-finding probability of 0.66 , and through the definition of the job-finding probability, a matching efficiency of 0.78. Silva and Toledo (2009) report that hiring costs amount to about $14 \%$ of quarterly employee compensation when expenses such as advertisement costs, agency fees, or travel costs for applicants are accounted for on top of the number of hours spent by company employees on recruiting. Thus, the vacancy posting cost is assumed to be equal to 
$\kappa=0.14 q w$. I can then back out the steady-state value of the real wage from the job creation equation. I obtain $w=\frac{m c}{1+0.14(1-\beta(1-\rho))}=0.82$ and $\kappa=0.11$. Given a calibrated value for the value of home production $b=0.4$, this implies a value for the exogenous bargaining power through the steady state wage equation $\eta=\frac{w-m c-\beta(1-\rho) \kappa \theta}{b-m c-\beta(1-\rho) \kappa \theta}$. Lastly, the social discount factor is assumed to be equal to the household discount factor $\xi=\beta$. When goods market are perfectly competitive, job creation in the zero-inflation steady state is efficient when $\eta=1-\alpha$ (Hosios 1990). With this calibration, job creation is too low both because of the presence of monopolistic competition and because $\eta$ differs from $1-\alpha$.

Figure 6 shows that the optimal inflation rate in this baseline calibration hovers around $1.6 \%$ in annual terms and is quite insensitive to the degree of wage stickiness $\phi^{w}$. Figure 7 shows that the optimal inflation rate increases with the degree of indexation of nominal wages to past inflation. Two effects are at play. First, for a given inflation rate, an increase in $\iota$ reduces the costs of wage adjustment, thereby freeing up a larger share of output available for consumption. It also raises the size of the surplus to be shared between workers and firms and, for a given value of $\tilde{\eta}$, boosts job creation. Second, increasing inflation becomes less effective at influencing job creation through the effective bargaining power $\tilde{\eta}$ as $\iota$ becomes larger. In this quantitative application, the first effect seems to dominate. Moreover, the optimal inflation rate remains positive even in the limit case where $\iota=1$. In that case, while the effects of inflation on wage markups are on average equal to zero, they are still distributed over time and real outcomes happening in different periods are weighted differently by the planner. Zero inflation is optimal only when this weighting effect is absent, that is when $\xi=1$, and prices are flexible (when $\xi=1$, the presence of sticky prices calls for positive inflation). 